\title{
The Ac-5 (Fejokoo) quadrangle of Ceres: Geologic map and geomorphological evidence for ground ice mediated surface processes
}

\author{
Kynan H.G. Hughson ${ }^{\mathrm{a}, *}$, C.T. Russella, D.A. Williams ${ }^{\mathrm{b}}$, D.L. Buczkowski ${ }^{\mathrm{c}}$, S.C. Mest ${ }^{\mathrm{d}}$, \\ J.H. Pasckert ${ }^{\mathrm{e}}$, J.E.C. Scully ${ }^{\mathrm{f}}$, J.-P. Combe ${ }^{\mathrm{g}}$, T. Platz $^{\mathrm{d}, \mathrm{h}}$, O. Ruesch ${ }^{\mathrm{i}}$, F. Preusker ${ }^{\mathrm{j}}$, R. Jaumann ${ }^{\mathrm{j}}$, \\ A. Nass ${ }^{j}$, T. Roatsch $^{j}$, A. Nathues ${ }^{h}$, M. Schaefer ${ }^{h}$, B.E. Schmidt ${ }^{k}$, H.T. Chilton ${ }^{k}$, A. Ermakov $^{f}$, \\ S. Singh ${ }^{g}$, L.A. McFadden ${ }^{i}$ C.A. Raymond ${ }^{\mathrm{f}}$ \\ a Department of Earth, Planetary, and Space Sciences, University of California Los Angeles, 595 Charles E. Young Drive East, Los Angeles, CA 90095, USA \\ ${ }^{\mathrm{b}}$ School of Earth and Space Exploration, Arizona State University, PO Box 871404, Tempe, AZ 85287-1404, USA \\ ' Johns Hopkins University Applied Physics Laboratory, 11100 Johns Hopkins Rd, Laurel, MD 20723, USA \\ d Planetary Science Institute, 1700 E Fort Lowell Rd \# 106, Tucson, AZ 85719, USA \\ e University of Münster, Schlossplatz 2, 48149 Münster, Germany \\ f Jet Propulsion Laboratory, 4800 Oak Grove Dr, Pasadena, CA 91109, USA \\ ${ }^{\mathrm{g}}$ Bear Fight Institute, 22 Fiddler's Rd, Winthrop, WA 98862, USA \\ ${ }^{\mathrm{h}}$ Max Planck Institute for Solar System Research, Justus-von-Liebig-Weg 3, 37077 Göttingen, Germany \\ i NASA Goddard Space Flight Center, 8800 Greenbelt Rd, Greenbelt, MD 20771, USA \\ j German Aerospace Center (DLR), Friedrichstraße 171, 10117 Berlin, Germany \\ ${ }^{\mathrm{k}}$ School of Earth ans Atmospheric Sciences, Georgia Institute of Technology, 311 Ferst Dr, Atlanta, GA 30318, USA
}

\section{A R T I C L E I N F O}

\section{Article history:}

Received 10 August 2016

Revised 18 September 2017

Accepted 26 September 2017

Available online 23 October 2017

\section{Keywords:}

Ceres

Dawn

Dwarf planet

Geologic map

Ground ice

\begin{abstract}
A B S T R A C T
NASA's Dawn spacecraft arrived at Ceres on March 6, 2015, and has been studying the dwarf planet through a series of successively lower orbits. Throughout these mission phases Dawn obtained photographic, mineralogical, elemental abundance, and gravity data. Ceres is the largest object in the asteroid belt with a mean diameter of $\sim 940 \mathrm{~km}$. The Dawn Science Team conducted a geologic mapping campaign for Ceres similar to the one that was implemented on the asteroid Vesta (Dawn's previous target), including production of a Survey- and High Altitude Mapping Orbit (HAMO)-based global map, and a series of 15 Low Altitude Mapping Orbit (LAMO)-based quadrangle maps. In this paper we present the LAMO-based geologic map of the Ac-5 Fejokoo Quadrangle $\left(21-66^{\circ} \mathrm{N}\right.$ and $\left.270-360^{\circ} \mathrm{E}\right)$ and discuss its implications. The Ac-5 quadrangle is primarily composed of ancient cratered terrain punctuated with several moderately fresh impact craters of geologic interest, six large tholi that are possibly cryovolcanic in origin, and an abundance of flows that well represent the full spectrum of mass wasting features observed on Ceres. The Fejokoo quadrangle hosts the majority of Oxo crater, the site of the first spectroscopic detection of $\mathrm{H}_{2} \mathrm{O}$ ice on the surface of Ceres. The $\mathrm{H}_{2} \mathrm{O}$ detection is closely related to two distinctive morphological units interpreted as possible high water ice content landslides. These observations and interpretations are consistent with ground ice mediated surface processes on Ceres.
\end{abstract}

(c) 2017 Elsevier Inc. All rights reserved.

\section{Introduction}

The dwarf planet (1) Ceres is the largest and most massive object in the main asteroid belt $(482.8 \mathrm{~km} \times 480.6 \mathrm{~km} \times 445.0 \mathrm{~km}$ $( \pm 0.2 \mathrm{~km}))$ with a geometric mean radius of $469.7 \mathrm{~km}$ and a total mass of $(9.38416 \pm 0.00013) \times 10^{20} \mathrm{~kg}$ (Park et al., 2016; Preusker et al., 2016). Ceres is the only recognized dwarf planet in the inner solar system and has a mean density of $2162 \pm 8 \mathrm{~kg} / \mathrm{m}^{3}$, which

\footnotetext{
* Corresponding author.

E-mail address: p151c@ucla.edu (K.H.G. Hughson).
}

suggests a composition that is rich in water ice and/or hydrated materials (Russell et al., 2016; Thomas et al., 2005; McCord and Sotin, 2005; Castillo-Rogez and McCord, 2010; Zolotov, 2009). Ceres is interpreted to be moderately differentiated into a core likely dominated by silicates, an ice-rich mantle, an anomalously ridged crust, and a thin outer lag deposit (Ermakov et al., 2016; CastilloRogez et al., 2016; De Sanctis et al., 2015). Like a handful of other large asteroids (e.g. 2 Pallas and 4 Vesta) Ceres is thought to have remained largely intact since its formation nearly $4.5 \mathrm{Ga}$ (Coradini et al., 2011). 
Since its discovery, Ceres has been studied extensively by both Earth and space based observatories. Hubble Space Telescope observations have determined that Ceres has an average geometric albedo of $\sim 0.09$ that in general displays very little global variability (Li et al., 2016). A solitary detection of $\mathrm{OH}$ emissions near the north pole (A' Hearn and Feldman, 1992), recent observations of $\mathrm{H}_{2} \mathrm{O}$ emissions by the Herschel Space Observatory (Küppers et al., 2014), potential viscous relaxation in large craters (Bland et al., 2016), and a controversial detection of sublimation processes in the Occator and Oxo regions using Dawn's Framing Camera (FC) (Nathues et al., 2015) suggest that water ice is substantially present in the shallow subsurface of Ceres (the Nathues et al., (2015) detection is disputed by Schröder et al., (2017) who claim to have been unable to reproduce the former's result using the same FC images or find evidence for haze in Occator using higher resolution images). The visible and near-IR spectral features of Ceres are typical of C-type asteroids, and are somewhat compatible with carbonaceous chondrite meteorites (Rivkin et al., 2006). Unlike Vesta, no meteorites have been convincingly linked directly to Ceres; this is mainly due to spectral discrepancies between Ceres and $\mathrm{CM}$ chondrites (the class of meteorites most spectrally similar to Ceres) in both the UV and $3 \mu \mathrm{m}$ region (Burbine, 1998). Recent Dawn observations using the Visible and InfraRed spectrometer (VIR; De Sanctis et al., 2011) have shown that the surface is relatively homogeneous, and ubiquitously contains carbonates and ammoniated phyllosilicates (De Sanctis et al., 2015; De Sanctis et al, 2016). The first observations of molecular $\mathrm{H}_{2} \mathrm{O}$ on the surface of Ceres were also made by VIR inside of Oxo crater, which is predominantly located within the Fejokoo quadrangle (Combe et al., 2016). Additional introductory information about Ceres is presented in the introductory paper to this Special Issue (Williams et al., 2017).

The Dawn Science Team conducted a geologic mapping campaign for Ceres similar to the one that was implemented on the asteroid (4) Vesta (Williams et al., 2014; Yingst et al., 2014), including the production of a Survey- and High Altitude Mapping Orbit (HAMO)-based global map (Roatsch et al., 2016a; Roatsch et al., 2016b), and a series of 15 Low Altitude Mapping Orbit (LAMO)based quadrangle maps. In this paper we present the detailed LAMO-based geologic map of the Ac-5 Fejokoo Quadrangle (21$66^{\circ} \mathrm{N}$ and $270-360^{\circ} \mathrm{E}$ ). Through the geologic mapping we address the following questions:

1. What is the nature of the tholi and mass wasting features in the Fejokoo quadrangle?

2. What do the tholi and mass wasting features tell us about the global properties of Ceres?

3. What is the geological context of Oxo crater and its $\mathrm{H}_{2} \mathrm{O}$ detection?

\section{Methods and datasets}

\subsection{Base data and basemaps}

The Ceres science segment of the Dawn mission started in March of 2015 and is ongoing as of September 2017. During this science phase data were acquired in four progressively lower altitude stages: (1) Approach ( $\geq 13,600 \mathrm{~km}$ altitude), (2) Survey orbit (4400 km altitude), (3) HAMO (1470 km altitude), and (4) LAMO (375 km altitude). These data were collected using Dawn's FC (Sierks et al., 2011), VIR (De Sanctis et al., 2011), Gamma Ray and Neutron Detector (GRaND) (Prettyman et al., 2011), and radio science package (Konopliv et al., 2011). The work in this paper is predominantly based on clear and color filter FC images and mosaics along with stereophotogrammetrically (SPG) derived digital terrain models (DTMs) of Ceres (vertical accuracy $\sim 10 \mathrm{~m}$ ) (Preusker et al., 2016). These FC data were acquired globally at $\sim 140 \mathrm{~m} /$ pixel and $\sim 35 \mathrm{~m} /$ pixel, from the HAMO and LAMO mission phases, respectively. FC color filter images were acquired with near global coverage during the HAMO mission phase, and of select features of interest during the LAMO phase. For details on the calibration of FC images see Schröder et al., (2013, 2014)).

Photometrically corrected FC mosaics of the Fejokoo quadrangle were also used to determine albedo variations within the quadrangle (for details on the method used to produce the photometrically corrected mosaic see Schröder et al., (2013)). Compositional data acquired by VIR was used to inform the map, in particular the variations in the depth of the 2.70 and $3.06 \mu \mathrm{m}$ absorption band associated with $\mathrm{OH}$ in phyllosilicates and ammoniated clay minerals, respectively and the $\mathrm{H}_{2} \mathrm{O}$ detection at Oxo (Combe et al., 2016). Bouger gravity anomaly maps derived from radio science observations were also used in the interpretation of the geologic map (Ermakov et al., 2016; Ermakov et al., 2017.; Konopliv et al., 2018.).

\subsection{Mapping methodology and tools}

In order to facilitate efficient and systematic geological mapping of Ceres the Dawn Science Team divided its surface into 15 quadrangles (Fig. 1). The individual quadrangles were named after the most prominent impact crater found within their borders. More details on the quadrangle schema and nomenclature theme for Ceres are found in the introductory paper to this Special Issue (Williams et al., 2017). Each quadrangle was assigned a principal mapper who completed the bulk of the geological mapping. Neighboring quadrangle mappers and VIR team spectroscopists also contributed significantly to the development these maps.

We completed geologic mapping using ArcMap 10.3 on a set of georeferenced, quadrangle wide, clear filter (panchromatic) FC mosaics and DTMs (Fig. 2 and Fig. 3a and 3b). In order to ensure cartographic consistency, a uniform set of GIS and map layout templates were employed over all 15 quadrangles. The maps were informed by ancillary data products mentioned in Section 2.1. Topographic profiles and surface feature measurements for the Ac5 geologic map (Fig. 4) presented here were obtained from the HAMO DTM and its derivative slope map (Fig. 5). A particularly useful HAMO color composite mosaic was also used in the production of this geologic map (Fig. 6). Known as color composite R, this mosaic assigns the FC color filter ratios $\frac{965 \mathrm{~nm}}{750 \mathrm{~nm}}$ to the red channel, $\frac{550 \mathrm{~nm}}{750 \mathrm{~nm}}$ to the green channel, and $\frac{440 \mathrm{~nm}}{750 \mathrm{~nm}}$ to the blue channel. In color composite $\mathrm{R}$, materials with a positive spectral slope appear reddish, while materials with a negative spectral slope appear blueish.

Crater size-frequency distributions (CSFDs) of surface units in this quadrangle were derived using CraterTools 2.1 developed by Kneissl et al., (2011; 2014; 2015). CraterstatsII (Micheal and Neukum, 2010) was used to analyze and fit the CSFDs to the lunar and asteroid derived production functions. Absolute model ages (AMAs) were generated by craterstatsII using the lunar and asteroid derived chronology functions from Hiesinger et al., (2016). The error assigned to the AMAs is the standard error of $\mathrm{N}(1)$ (the number of counted craters $>1 \mathrm{~km}$ in diameter per unit area) calculated as follows:

$\sigma= \pm \mathrm{N}_{\text {cumulative }} * \frac{1}{\sqrt{n}}$

Where $n$ is the total number of fitted craters (Arvidson et al., 1979; Michael and Neukum, 2010). 

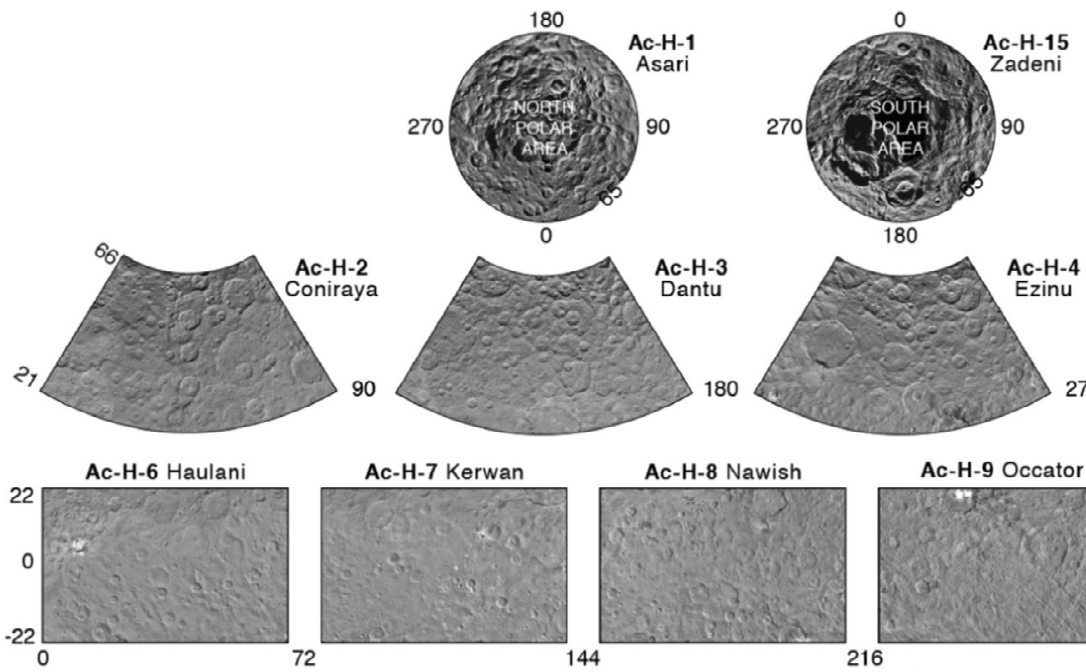

Ac-H-8 Nawish

Ac-H-9 Occato
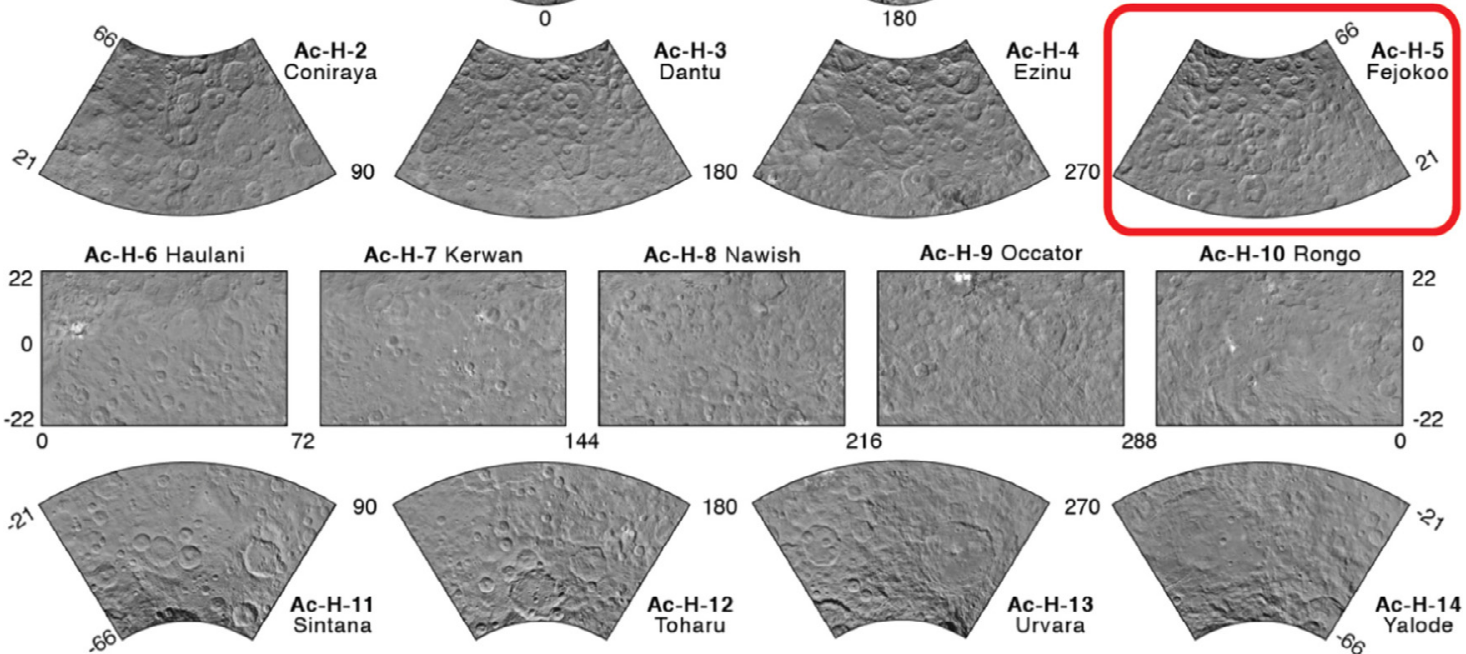

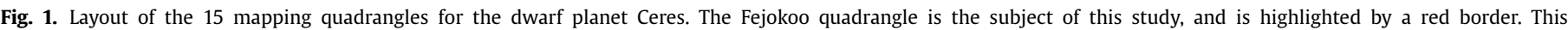

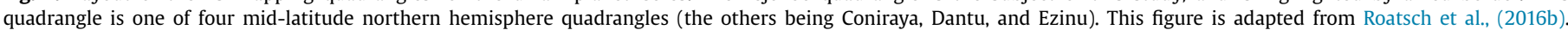
(For interpretation of the references to color in this figure legend, the reader is referred to the web version of this article.)

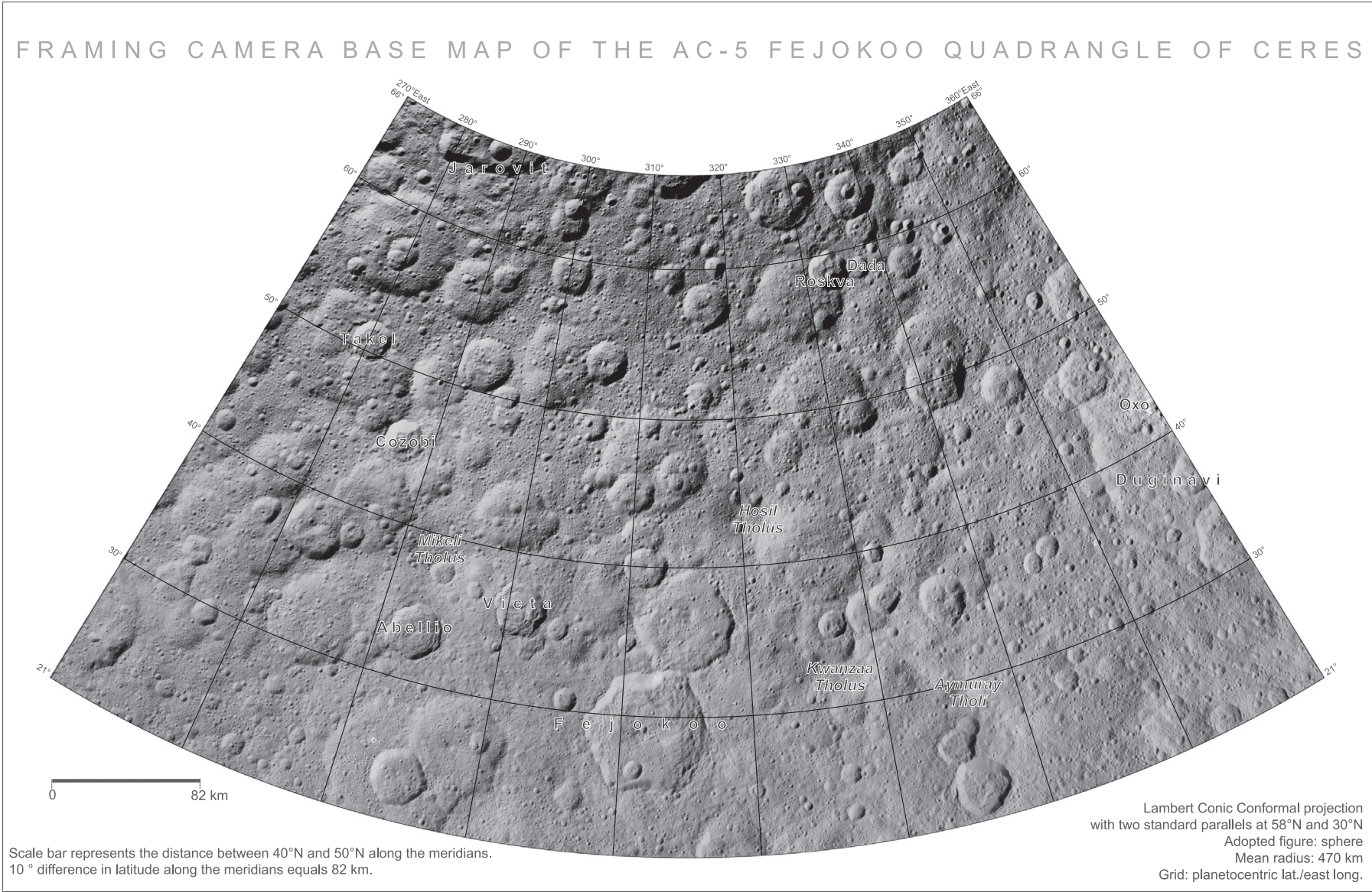

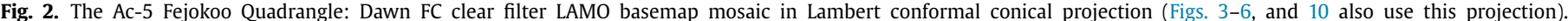
Basemap mosaics, which have a resolution of $\sim 35 \mathrm{~m} /$ pixel, were rendered following methods outlined in Roatsch et al., (2016b). 

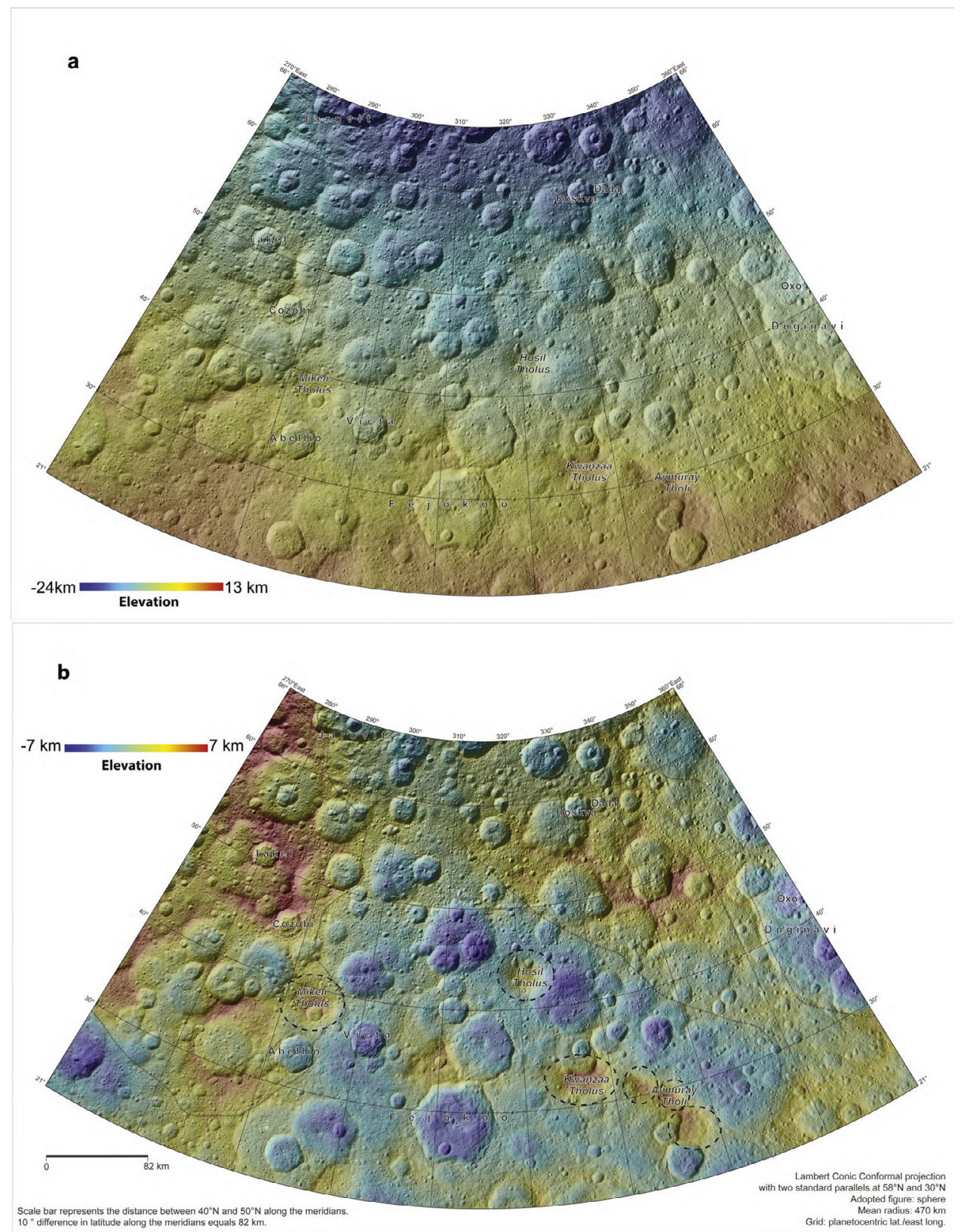

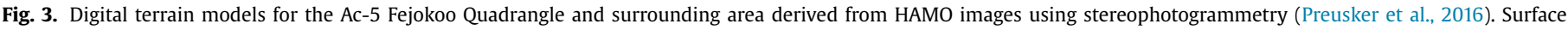

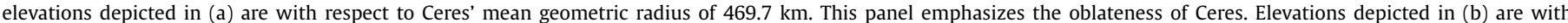

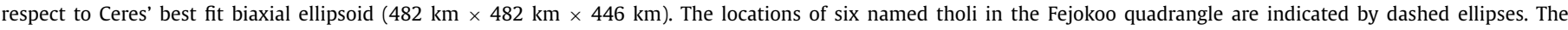

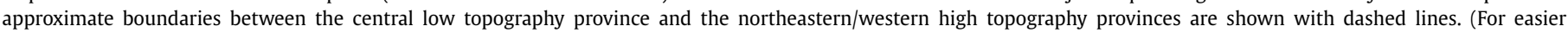
interpretation of this figure, the reader is referred to the color version of this figure found within the web edition of this article.)

\section{Results}

\subsection{Geologic setting}

The Ac-5 Fejokoo Quadrangle is one of four mid-latitude northern hemisphere cartographic quadrangles on Ceres (Fig. 1). The Fejokoo quadrangle's entire extent is dominated by heavily cratered terrain. This region represents a major fraction of the most densely cratered areas on Ceres, which implies it is one of the most ancient terrains on the surface (Hiesinger et al., 2016). The Fejokoo quadrangle is bordered on the west and southwest by the Ac-4 Ezinu (Scully et al., 2017) and Ac-9 Occator (Buczkowski et al., 2017) quadrangles, respectively. These adjacent regions are gener- ally more sparsely cratered than the Fejokoo quadrangle. The dominant geological feature in the Ac-4/Ac-9 region is Occator crater and the surrounding topographic high, Hanami Planum. To the south of the Fejokoo quadrangle lies the topographically depressed, relatively sparsely cratered, Ac-10 Rongo Quadrangle (Platz et al., 2017). Despite the general low lying nature of the Ac-10 Rongo Quadrangle it contains numerous broad topographic rises and tholi (singular, tholus, meaning domical mountain or hill) including Ahuna Mons, a large, roughly symmetric, smooth sided edifice whose origin is possibly cryovolcanic (Ruesch et al., 2016). To the east is the Ac-2 Coniraya Quadrangle (Pasckert et al., 2017), which is dominated by Coniraya, Omonga, and other large impact craters. The Fejokoo quadrangle is capped to the north by the Ac- 1 Asari 


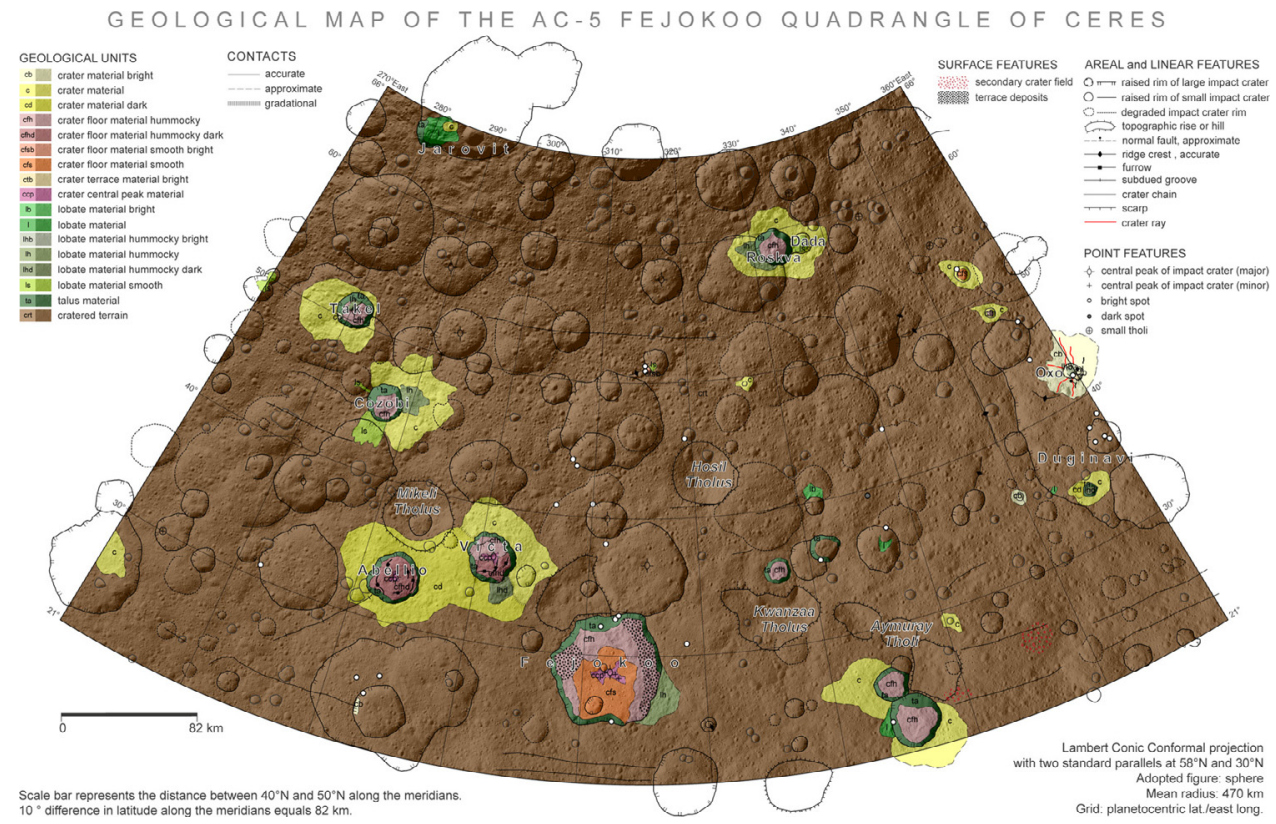

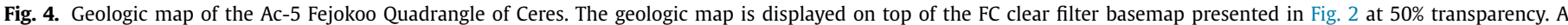

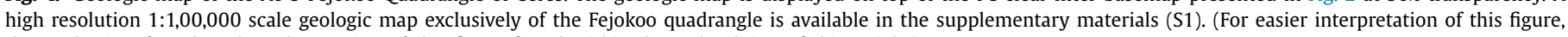
the reader is referred to the color version of this figure found within the web edition of this article.)

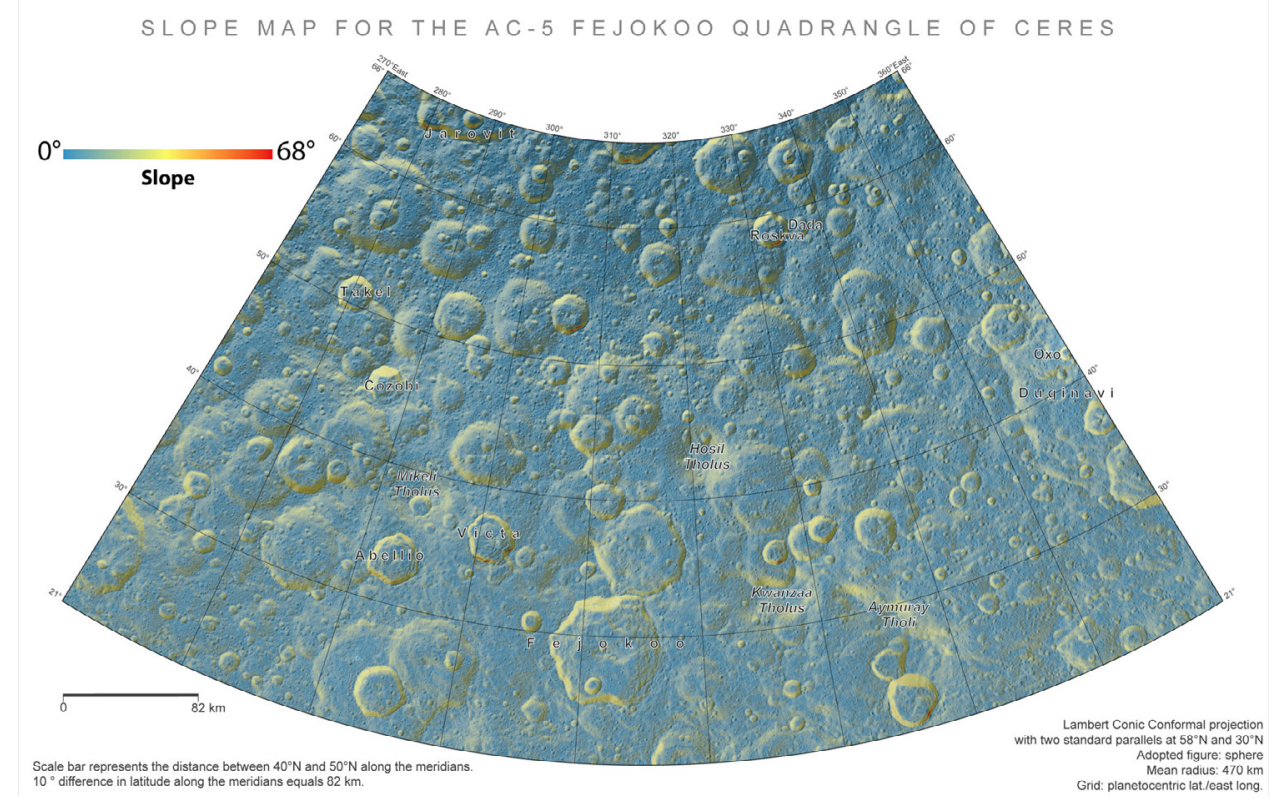

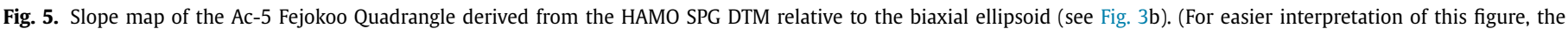
reader is referred to the color version of this figure found within the web edition of this article.)

north pole quadrangle (Ruesch et al., 2017), whose geology is dominated by densely cratered terrain and a high degree of topographic variability.

\subsection{Topography}

The surface elevation of the Fejokoo quadrangle with respect to the best-fit biaxial ellipsoid $(482 \mathrm{~km} \times 482 \mathrm{~km} \times 446 \mathrm{~km})$ for Ceres is shown in Fig. 3b. The Fejokoo quadrangle displays three general topographic provinces: a long, quasi-wedge shaped region of considerably high topography along the western margin, an irregular region of moderately high topography in the northeast, and a large central low lying area dominated by degraded impact craters and several large domical tholi that are not strongly associated with impact craters (Fig. 3 b).

The high-topography western province, which sits $\sim 2500 \mathrm{~m}$ above the best-fit ellipsoid, spans $\sim 600 \mathrm{~km}$ in length from the north pole south towards Abellio crater and sweeps out an area westward to approximately $265^{\circ} \mathrm{E}$. This province has an average width of $\sim 150 \mathrm{~km}$ within the Fejokoo quadrangle.

The moderately high northeastern topographic province is located immediately west of Oxo crater and south of Roskva and Dada craters. It spans $\sim 300 \mathrm{~km}$ east-to-west and $\sim 150 \mathrm{~km}$ northto-south. This region, which sits $\sim 1900 \mathrm{~m}$ above the average ellipsoid, is broadly domical compared to the plateau like nature of the western high topography province. 


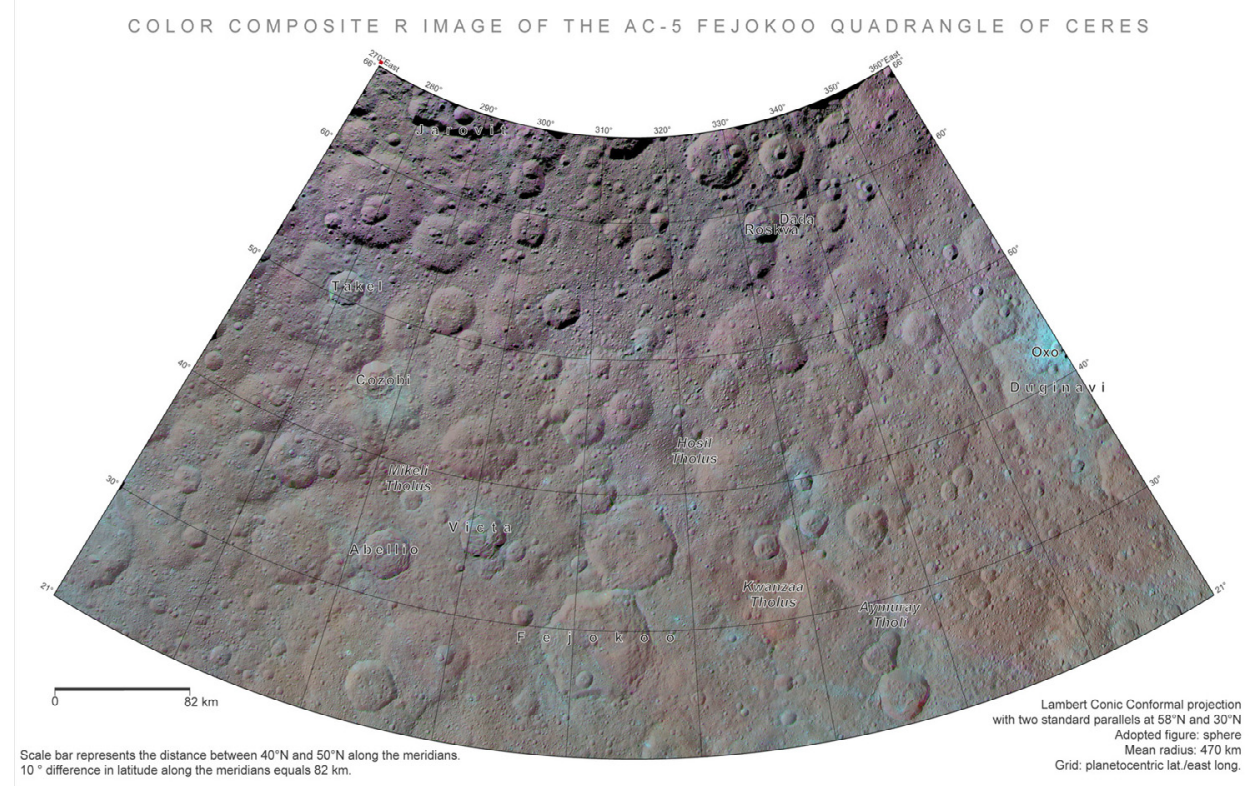

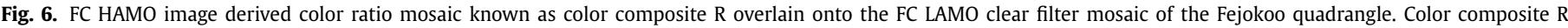

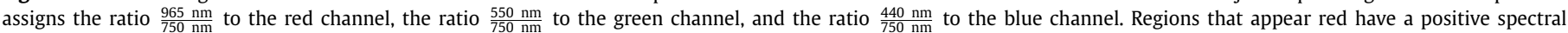

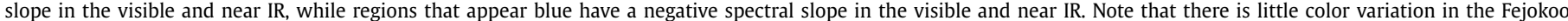

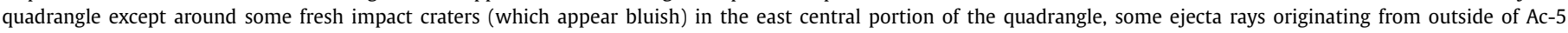

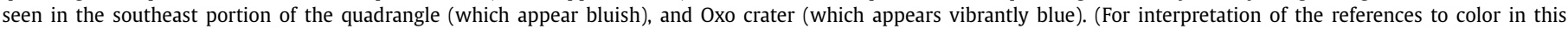
figure legend, the reader is referred to the web version of this article.)

The low lying central region of the Fejokoo quadrangle, which contains Victa and the namesake Fejokoo crater, is the northernmost extension of a large depressed province that dominates the topography of the Ac-10 Rongo Quadrangle. This region has been identified as a large, potential, degraded impact basin by Marchi et al., (2016). The extension of this low lying area in the Fejokoo quadrangle, which is on average $\sim 2000 \mathrm{~m}$ below the average ellipsoid, displays many of the same geologic and morphologic characteristics as the Rongo quadrangle; in particular, the presence of large quasi-symmetric domical tholi. These tholi provide significant positive relief of $\sim 2-4 \mathrm{~km}$ above the background topography in an otherwise low-lying region. The tholi present in this low-lying province are discussed further in Section 3.4.1.

\subsection{Description of map units}

Seventeen different geologic units are identified on the geologic map of the Fejokoo quadrangle presented in Fig. 4, and on the 1:1000,000 scale geologic map presented in the supplementary material (S1). FC images of type locations for each major unit class are presented in Fig. 7. Geologic units were defined primarily by textural and morphologic characteristics observed in FC clear filter images and the HAMO DTM. Reflectance and spectral features were also employed in the identification of map units.

\subsubsection{Cratered terrain (crt)}

This unit represents the background material of the Fejokoo quadrangle, and is found ubiquitously throughout the quadrangle. It is defined as area with a high concentration of impacts craters and no other distinguishing characteristics (Fig. 7a). The craters in this unit are predominantly degraded and rarely have discernable ejecta. In the FC enhanced-color ratio image (color composite R: Fig. 6), this unit appears a brownish-red color throughout the Fejokoo quadrangle with little variation. This unit does not cross-cut any other geologic units. Interpretation: This unit is interpreted to be the most ancient cerean material present in the Fejokoo quad- rangle based on its relative uniformity and high density of degraded craters of all sizes less than $200 \mathrm{~km}$ in diameter (Hiesinger et al., 2016).

\subsubsection{Crater material (c)}

This unit represents material external to an individual crater that has modified the background cratered terrain substantially in either texture or morphology (Fig. 7b). These modifications are usually a softening of the underlying topography, sheeted, fluted, or furrowed layer deposits; and occasional linear to curvilinear material streaks. Interpretation: These units are the result of relatively recent impacts into the Fejokoo quadrangle, and appear to degraded quickly over time. Typically, this material is excavated from the parent crater (ejecta), but it can also be non-lobate mass wasting on the outward facing rim of parent craters.

3.3.2.1. Crater material bright ( $c b)$ and crater material dark ( $c d)$. The crater material unit group also contains two sub-groups: crater material bright and crater material dark. The distinguishing criterion between these three units is the reflectance measured in photometrically corrected FC images. Crater material bright has a higher reflectance than the immediate surrounding units, crater material dark has a lower reflectance than the surrounding units, and crater material has generally the same reflectance as surrounding units.

\subsubsection{Crater floor materials}

3.3.3.1. Crater floor materials hummocky (cfh) and crater floor material hummocky dark (cfhd). These units, found on the floors of impact craters, are characterized by concentric furrows, terraces, and/or occasionally bulbous mounds. Again, the distinguishing criterion between these units is their reflectance compared to proximal background material. Interpretation: These units are disproportionately present in seemingly young craters (at least relative to the age of the ubiquitous cratered terrain), which imply that they degrade significantly over geologic time. Examples of these units 


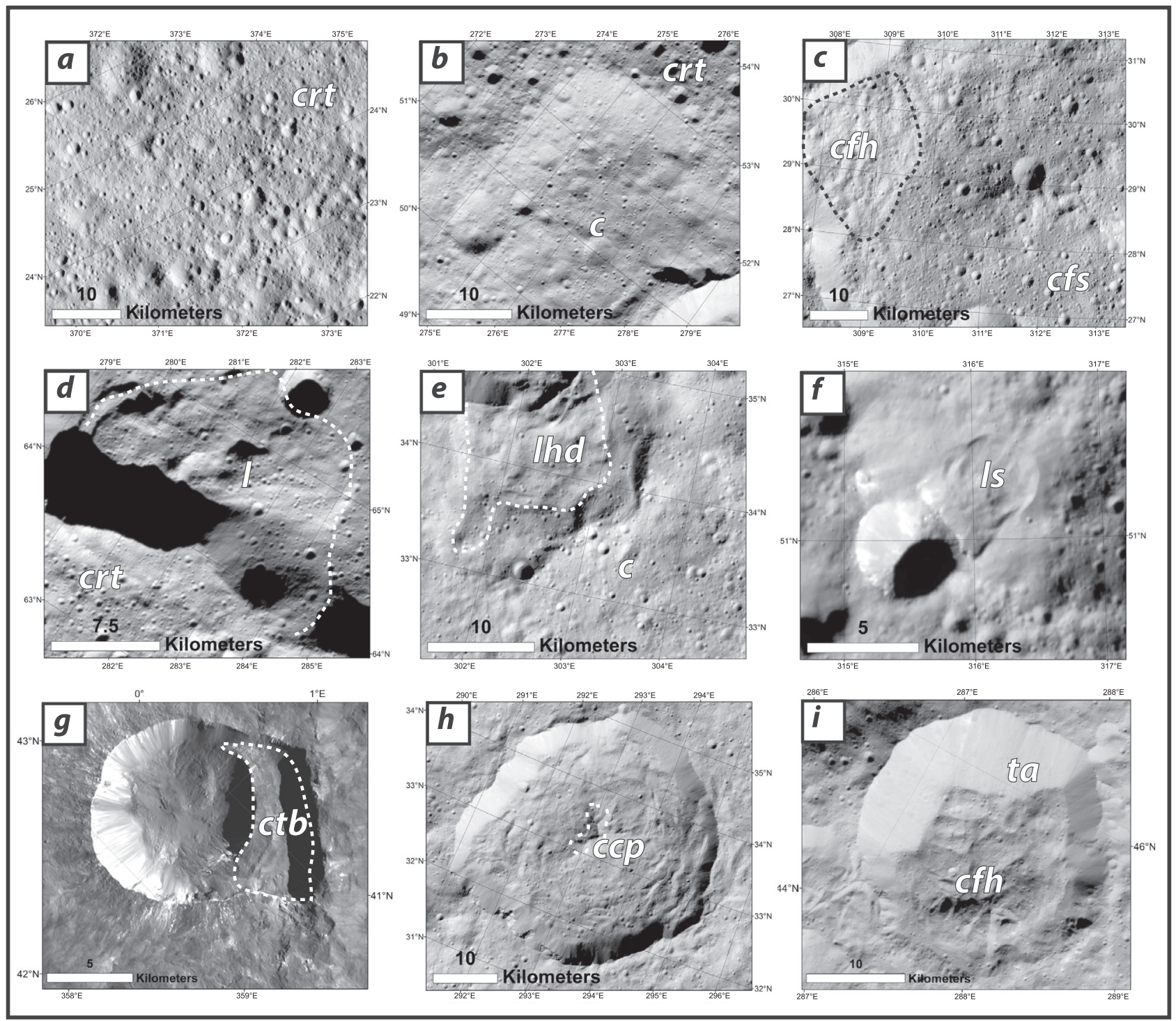

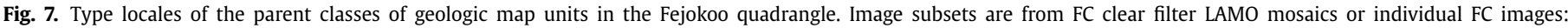

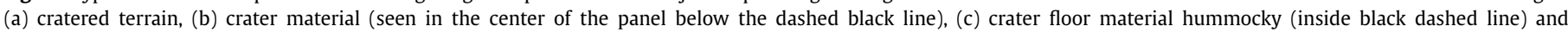

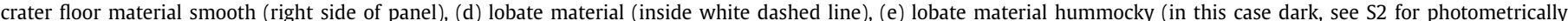

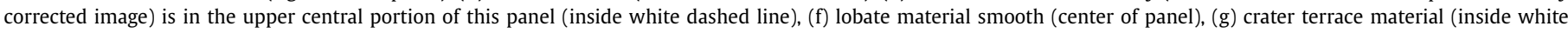

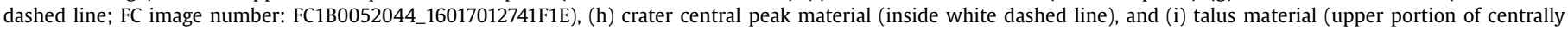
located impact crater). A larger version of this figure is available in the supplementary materials (S3).

that contain concentric terraces and/or a 'pinwheel' like texture (e.g. Fig. $7 \mathrm{~h}$ ) are interpreted as being similar to transient crater collapse features on the icy satellites of Jupiter, Saturn, and Uranus (Schenk, 1989; Hiesinger et al., 2016). Thus the geomorphology of cfh and cfhd units with concentrically and/or 'pinwheel' terraced floors may be an indication that the upper layer of Ceres is rheologically similar to those of outer solar system satellites; at least proximally to where these units occur. In the case of $c f h$ or $c f h d$ units that do not have 'pinwheel' structures or concentric terraces (e.g. Fig. 7c) we interpret them as similar to slumps found in the interiors of lunar and Mercurian craters.

3.3.3.2. Crater floor material smooth (cfs) and crater floor material smooth bright ( $c f s b)$. These units are morphologically non-descript like the floors of craters found in the ubiquitous cratered terrain unit. The major differences between smooth crater floor material and cratered terrain are that smooth crater floor material is relatively less densely cratered, and is qualitatively less rough. Again, the distinguishing criterion between these units is their relative brightness compared to the immediate surrounding material. Interpretation: These units may represent an intermediate degradational state between hummocky crater floor material and cratered terrain; alternatively, they may represent rheological heterogeneities within the upper layer of Ceres.

\subsubsection{Lobate material (l)}

This family of units are found both inside and outside of, but always associated with, impact craters. They are characterized by continuous deposits with well defined arcuate to linear margins, frontal lobes or snouts, and positive topographic relief relative to surrounding material (Fig. 7d). The lobate material bright (lb) unit is differentiated from lobate material based on the relative brightness of the surrounding units. Interpretations: These lobate deposits are most frequently associated with distinctive scarps and appear to have down-slope directionality, as such they are predominantly interpreted as various forms of mass wasting such as debris flows, 
Table 1

Approximate representative morphometric values for major tholi in the Fejokoo quadrangle and Ahuna Mons. Semi-major and semi-minor axes were determined using dominant breaks in slope around the tholi or Mons in question.

\begin{tabular}{lllll}
\hline Tholus name and location & Semi-major axis $(\mathrm{km})$ & Semi-minor axis $(\mathrm{km})$ & Quadratic mean radius $(\mathrm{km})$ & Prominence $(\mathrm{km})$ \\
\hline South Aymuray: $26^{\circ} \mathrm{N}, 337^{\circ} \mathrm{E}$ & 24 & 20 & 22 & 3.5 \\
Central Aymuray: $29^{\circ} \mathrm{N}, 336^{\circ} \mathrm{E}$ & 13 & 11 & 12 & 3.0 \\
North Aymuray: $31^{\circ} \mathrm{N}, 334^{\circ} \mathrm{E}$ & 17 & 11 & 28 & 3.1 \\
Kwanzaa: $32^{\circ} \mathrm{N}, 327^{\circ} \mathrm{E}$ & 35 & 19 & 20 & 3.0 \\
Hosil: $43^{\circ} \mathrm{N}, 320^{\circ} \mathrm{E}$ & 20 & 19 & 19 & 3.1 \\
Mikeli: $38^{\circ} \mathrm{N}, 294^{\circ} \mathrm{E}$ & 20 & 18 & 17 & 4.2 \\
Ahuna Mons: $11^{\circ} \mathrm{S}, 316^{\circ} \mathrm{E}$ & 21 & 13 & & \\
\hline
\end{tabular}

impact and/or gravitationally induced landslides, and ice-cemented flows. Occasionally these flows have no obvious head scarps, and in these cases are interpreted as a form of fluidized ejecta.

3.3.4.1. Lobate material hummocky (lh), lobate material hummocky dark (lhd), and lobate material hummocky bright (lhd). These units are distinguished from lobate material by the presence of elongated mounds and rolls on their surface (Fig. 7e). These hummocks typically have characteristic heights of several tens of meters, widths of hundreds of meters, and long-axis lengths of hundreds to several thousands of meters. The long-axis of these features are typically aligned perpendicular to the downslope direction, except in Oxo crater. The lobate material hummocky dark and bright units are differentiated from the lobate material hummocky unit based on the relative brightness of the surrounding units. Interpretation: These features are interpreted as slumps and landslides within the Fejokoo quadrangle, and possibly fluidized ejecta for the incidence of hummocky lobate material to the east of Cozobi.

3.3.4.2. Lobate material smooth (ls). This unit has fewer surface features compared to other lobate material units, often starting from the rims of impact craters and running downslope (Fig. 7f). They have a characteristic rounded appearance, and are often found with several superimposed deposits lying on top of one another. Interpretation: These units are likely formed directly or indirectly as impact triggered landslides. The Cozobi crater ls deposits are possibly a form of fluidized ejecta.

\subsubsection{Crater terrace material bright (ctb)}

This unit, seen only within Oxo crater, demarks the unusual terrace block in the southeastern portion of the crater. Its surface is generally smooth and devoid of impact craters (Fig. $7 \mathrm{~g}$ ). Notable surface features within this unit are open fissures and fault scarps (see Section 3.3.2.8). Interpretation: This block is interpreted as a slump originating from the bounding ridge southeast of Oxo that collapsed towards its center. It was likely initiated post-impact during the collapse of the transient cavity.

\subsubsection{Crater central peak material (ccp)}

This unit comprises the prominent central peaks of several complex craters in the Fejokoo quadrangle (Fig. 7h). Characteristic features of this unit include a distinctive break in slope at its boundary, a conical topographic profile rising several hundreds of meters above the surrounding terrain, and a lower impact crater density than neighboring materials. Interpretation: These units are rebounded material created during the impact and post-impact collapse phases.

\subsubsection{Talus material (ta)}

This unit is defined as non-descript slope material and otherwise unclassified slope related deposits. It is generally smooth, but in some cases displays a knobby texture (Fig. 7i). It is always associated with the inward facing rims of impact craters. Interpretations: These talus slopes are likely highly unconsolidated granular materials resting at their angle of repose. They are interpreted as relatively young granular mass wasting and scree type deposits covering the walls of impact craters.

\subsection{Geologic features}

\subsubsection{Tholi}

Six tholi of interest exist within the Fejokoo quadrangle (Fig. 3b): South Aymury $\left(26^{\circ} \mathrm{N}, 337^{\circ} \mathrm{E}\right)$; Central Aymuray $\left(29^{\circ} \mathrm{N}\right.$, $\left.336^{\circ} \mathrm{E}\right)$; North Aymuray $\left(31^{\circ} \mathrm{N}, 334^{\circ} \mathrm{E}\right)$; Kwanzaa $\left(32^{\circ} \mathrm{N}, 327^{\circ} \mathrm{E}\right)$; Hosil $\left(43^{\circ} \mathrm{N}, 320^{\circ} \mathrm{E}\right)$; and Mikeli $\left(38^{\circ} \mathrm{N}, 294^{\circ} \mathrm{E}\right)$. These tholi share several common characteristics, including: prominence, diameter, profile, geographic affinity, and in some cases composition (see Table 1). These mounds have semi-major axes that fall in the range 13-24 km, an aggregate average mean quadratic radius of $19 \mathrm{~km}$, and an average prominence of $3.3 \mathrm{~km}$. In general, these tholi display broad circular to elliptical symmetry in their footprints with the exception of Kwanzaa and South Aymuray. These tholi have more irregular perimeters due to excavation by proximal impacts. The six tholi in the Fejokoo quadrangle are found only in the cratered terrain geologic unit, and all but the western-most tholus (Mikeli) exist in the south central low topography province. In profile, these features are broadly domical (i.e. concave-down), have moderately steep slopes, and have plateau-like flat region near their summits (Fig. 8). The flanks of the Fejokoo quad tholi have typical slopes of $\sim 20^{\circ}$ with a maximum measured slope of $\sim 35^{\circ}$ on Central Aymuray; for comparison, Ahuna Mons' smooth flanks have a typical slope of $\sim 35^{\circ}$ and a maximum slope of $\sim 42^{\circ}$.

The four southeastern most tholi are also located within a regional positive Bouger gravity anomaly with a maximum value of $\sim 140$ mGal (Fig. 9); although, they only appear weakly correlated with the center of the anomaly. This indicates that the region associated with the anomaly is isostatically overcompensated, which is consistent with the surrounding low topography province but unusual for such large edifices. The other prominent tholi in the Fejokoo quadrangle are not associated with any discrete gravity anomaly.

In addition to the aforementioned properties, Hosil, Mikeli, Central Aymuray, and to a lesser extent North Aymuray and Kwanzaa share similar spectral properties at $2.70 \mu \mathrm{m}$ and $3.06 \mu \mathrm{m}$ as observed by the VIR spectrometer (Fig. 10). Increased band depth at $2.70 \mu \mathrm{m}$ has been interpreted to represent an increased local abundance of phyllosilicate minerals in the regolith observable by VIR, whereas larger band depth at $3.06 \mu \mathrm{m}$ has been interpreted to represent an increased abundance of ammoniated clay minerals in the regolith observable by VIR (De Sanctis, 2015). The aforementioned tholi are all distinguished as similar extreme points in the Fejokoo quadrangle with respect to their band depth values at 2.70 and $3.06 \mu \mathrm{m}$ (Fig. 10b). In general, these features are interpreted to have a lower concentration of ammoniated clays, and a 

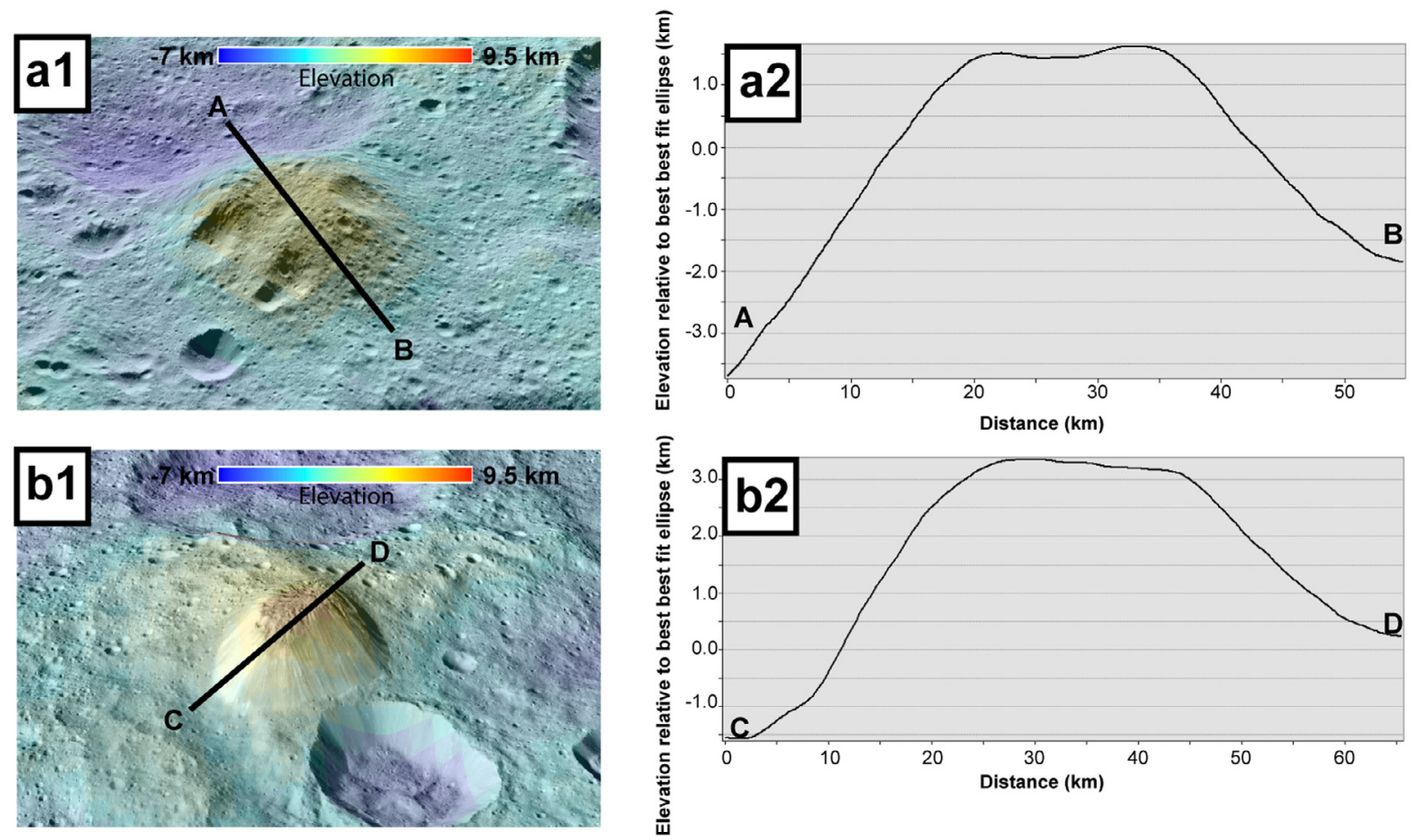

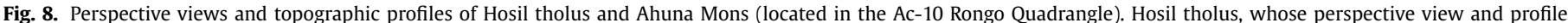

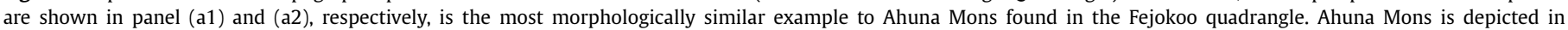

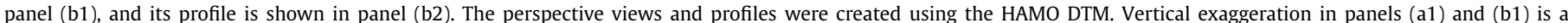

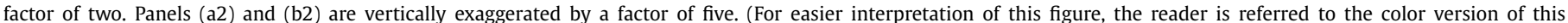
figure found within the web edition of this article.)
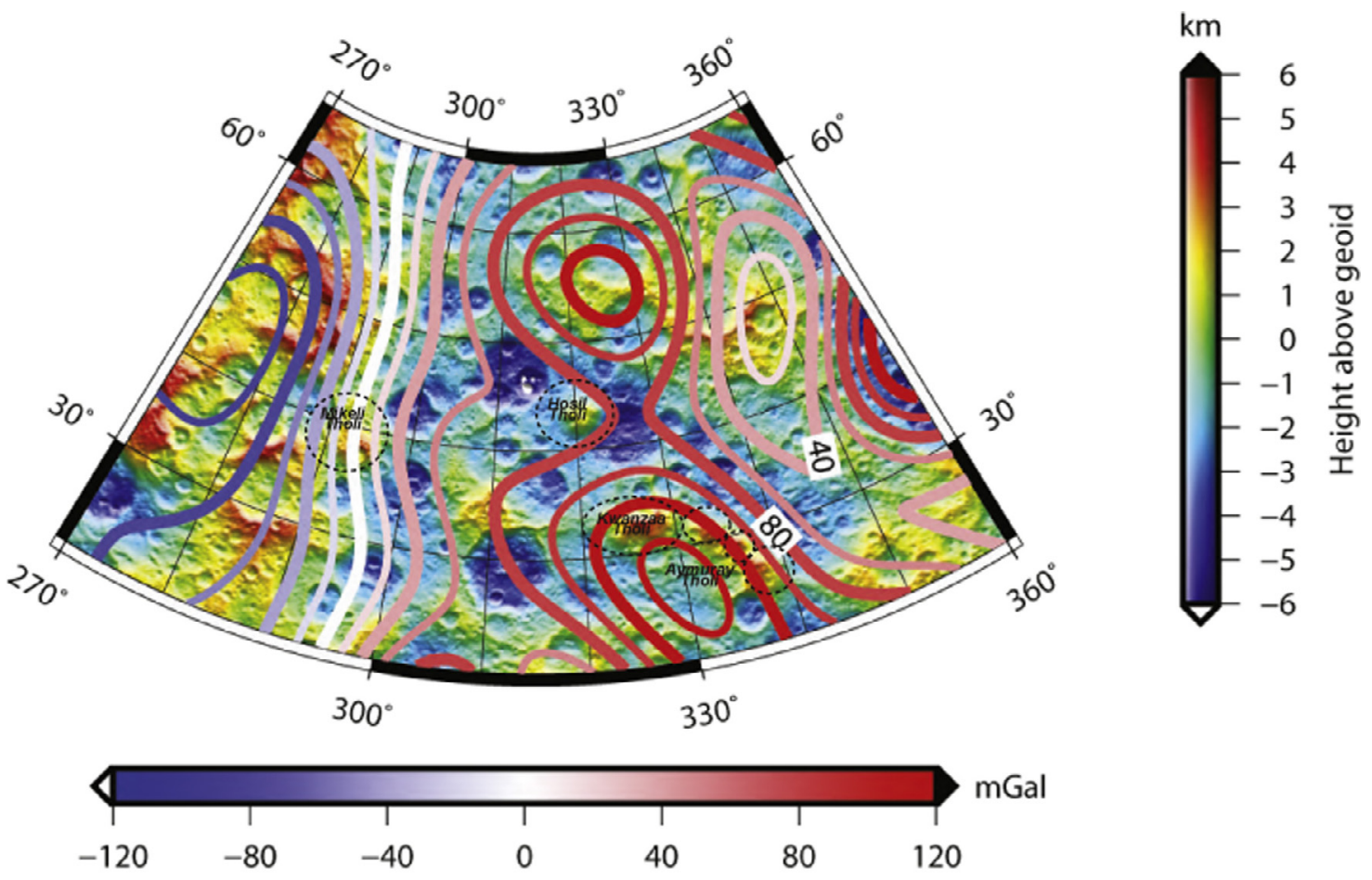

Bouguer gravity anomaly

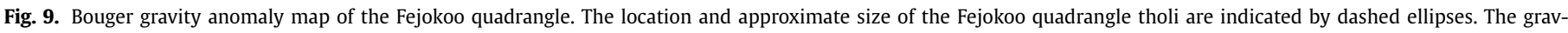

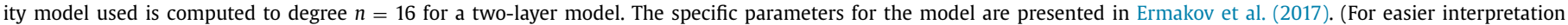
of this figure, the reader is referred to the color version of this figure found within the web edition of this article.) 

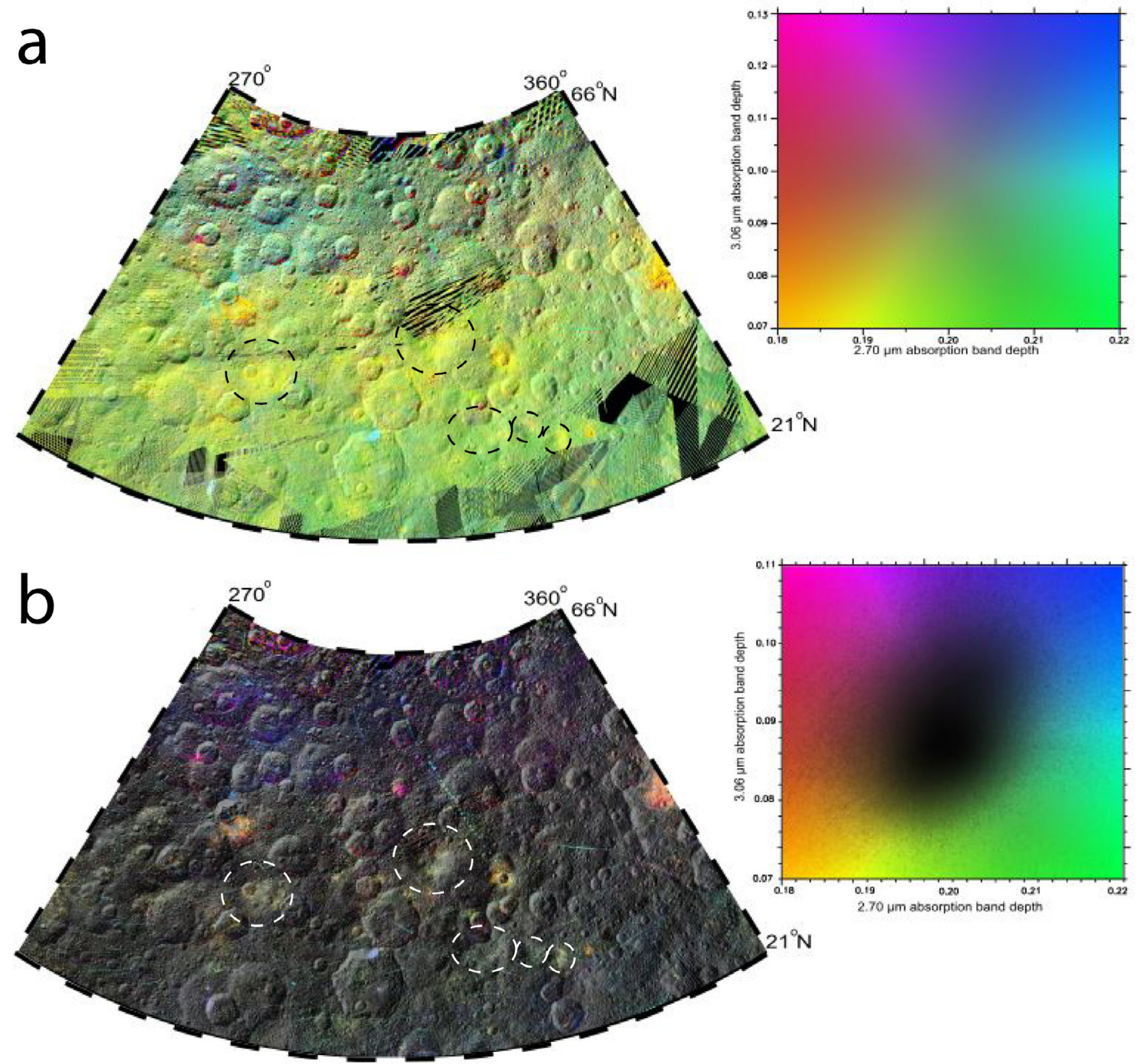

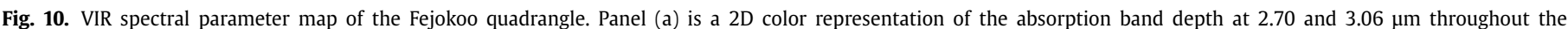

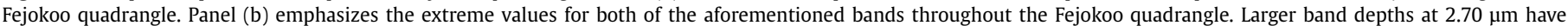

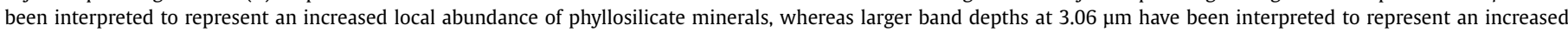

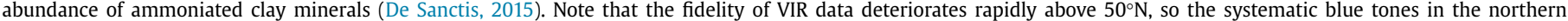

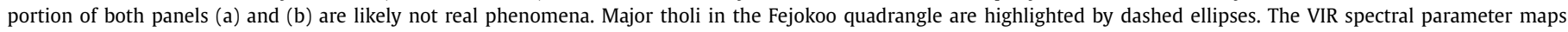

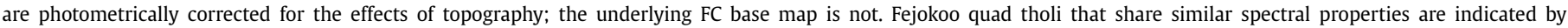
dashed white ellipses. (For interpretation of the references to color in this figure legend, the reader is referred to the web version of this article.)

slightly higher abundance of phyllosilicate minerals, than the average Fejokoo quadrangle background material. Factors like surface texture and grain size can also influence spectral properties, so if these tholi are not compositionally related they are at the very least chemically and/or physically different than the average Fejokoo quadrangle.

\subsubsection{Craters}

At the time of this writing, the Fejokoo quadrangle has 10 impact craters with names recognized by the IAU (International Astronomical Union): Fejokoo, Abellio, Victa, Cozobi, Takel, Jarovit, Roskva, Dada, Oxo, and Duginavi.
3.4.2.1. Fejokoo crater. Centered at $29^{\circ} \mathrm{N}, 312^{\circ} \mathrm{E}$ within the low lying topographic province of the Fejokoo quadrangle, the $68 \mathrm{~km}$ mean diameter Fejokoo is the largest well preserved polygonal impact structure on Ceres. Its perimeter closely approximates an equilateral hexagon (Fig. 11a). Like most craters on Ceres with diameters $\geq 20 \mathrm{~km}$ Fejokoo displays generally steep crater walls (slopes in some areas exceed $45^{\circ}$ ) and a largely flat floor. The smooth crater floor sits on average $\sim 5 \mathrm{~km}$ below the surrounding terrain, and is disrupted only by the $\sim 1 \mathrm{~km}$ high central peak complex and collapsed crater wall material/terraces that are found near the northwestern and southeastern rims. In general, Fejokoo exhibits radially symmetric topography with minor departures from this symmetry around the collapsed southeast rim. 

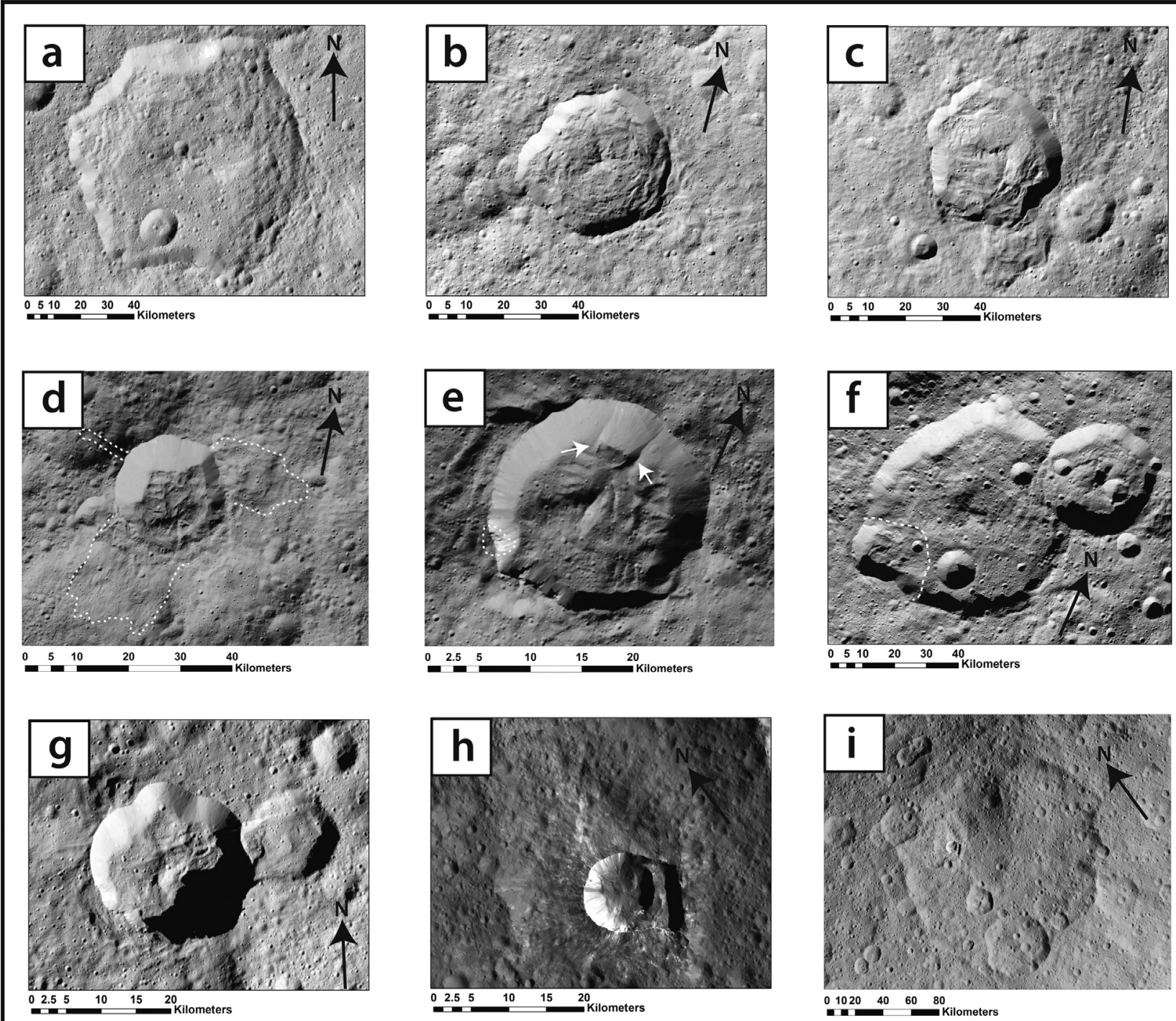

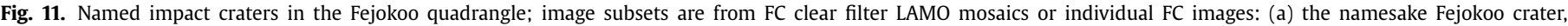

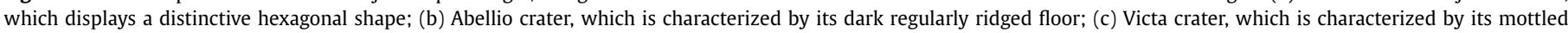

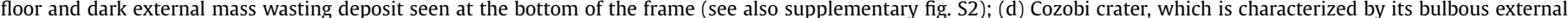

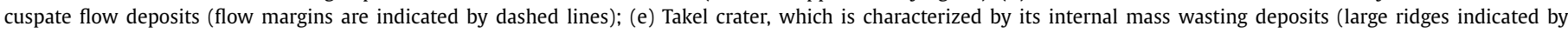

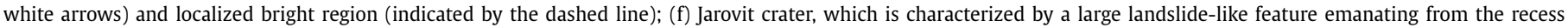

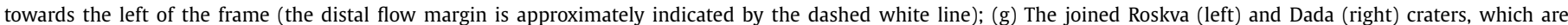

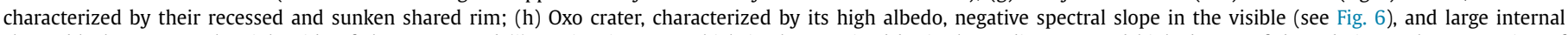

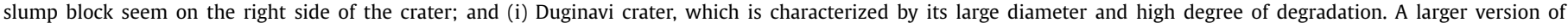
this figure is available in the supplementary materials (S4).

Streaks of bright material hundreds of meters wide and $\sim 5 \mathrm{~km}$ long are found on the inward facing slope of the north crater rim.

3.4.2.2. Abellio crater. This $32 \mathrm{~km}$ diameter crater centered at $33^{\circ} \mathrm{N}$, $293^{\circ} \mathrm{E}$ is located on the boundary of the western high and central low topography provinces. Abellio exhibits a topographically asymmetric floor that is systematically higher in the west and depressed in the east. This is likely because of its location in this transitional region (Figs. 3b and 11b). Like Fejokoo, Abellio exhibits a relatively flat crater floor (situated $\sim 2500 \mathrm{~m}$ below its mean rim height), a central peak (that rises $\sim 500 \mathrm{~m}$ above the crater floor), and steep crater walls ( $\sim 45^{\circ}$ median slope). Abellio's floor also displays prominent concentric ridges and terraces that are morphologically similar to those found in craters on icy satellites (Schenk, 1989; Porco et al., 2005). Photometrically corrected FC images also identify Abellio and its surrounding ejecta as being composed of distinctly lower albedo material than the surrounding terrain (see supplementary fig. S2). Abellio's features appear only moderately degraded compared to the adjacent terrain; this coupled with a low crater density on the floor and surrounding ejecta blanket imply it is a relatively fresh crater in the Fejokoo quadrangle.

3.4.2.3. Victa crater. $32 \mathrm{~km}$ in diameter and located just east of Abellio (centered at $36^{\circ} \mathrm{N}, 301^{\circ} \mathrm{E}$ ), Victa crater (Fig. 11c) is similar in most ways to Abellio. Victa differs from Abellio in three distinct categories: (1) its floor and rim planes are much more parallel to the local tangent plane of the Ceres best-fit ellipsoid due to its location entirely within the low topography province, (2) it has far fewer concentric terraces and their spacing is much more irregular, and (3) although darker than the average background material in the Fejokoo quadrangle it displays a higher albedo on average than Abellio (see supplementary fig. S2). A large dark hummocky lobate 
deposit $\sim 12 \mathrm{~km}$ long by $\sim 8 \mathrm{~km}$ wide stretches radially outward from the southern rim of Victa into a local depression that is likely the remnant of a pre-existing impact crater. This deposit is interpreted as a combination of Victa ejecta whose collection was locally enhanced by the presence of a depression and collapsed Victa crater rim material. Victa's ejecta darkens gradationally from east to west. Like Abellio, Victa also appears relatively fresh, but the cross-cutting relationships between Abellio, Victa, and their ejecta are ambiguous.

3.4.2.4. Cozobi crater. Centered at $45^{\circ} \mathrm{N}, 287^{\circ} \mathrm{E}$, the $24 \mathrm{~km}$ diameter Cozobi crater displays a distinctly asymmetric rim profile (Fig. 11d). The southern portion of the crater rim is almost completely collapsed displaying relief $1 \mathrm{~km}$ above the crater floor. This is in contrast with the northern rim, which rises $\sim 6 \mathrm{~km}$ above the crater floor. This is a possible indication that the impact was into steep terrain, or that the impact itself was quite oblique. Cozobi's floor exhibits a bumpy texture consisting of several large domes. The floor also contains some curvilinear ridges and terraces. Cozobi has a continuous ejecta deposit to its north and east, which display radial furrowing, increased textural softness compared to the surrounding terrain, and gradational boundaries with no detectable topographic signature, but is lacking these features around the remainder of its circumference. Instead, three prominent lobate flows features are seen emanating radially away from the southern, eastern, and western rims. The western flow is $\sim 12 \mathrm{~km}$ long by $\sim 1.5 \mathrm{~km}$ wide with total drop height of $\sim 2.6 \mathrm{~km}$. It is morphologically smooth at LAMO resolution, and displays a mass concentration at its terminus in the form of a bulbous snout. The eastern flow is morphologically similar the previous flow, but is significantly larger. This flow extends $\sim 18.5 \mathrm{~km}$ radially outward from the eastern rim, is $\sim 12 \mathrm{~km}$ wide at its origin, and has a total drop height of $\sim 3.5 \mathrm{~km}$. The southern flow is considerably larger than the previous two cases measuring $\sim 25 \mathrm{~km}$ long by $\sim 18 \mathrm{~km}$ wide with a total drop height of $\sim 4.1 \mathrm{~km}$. The flow is structured into numerous small v-shaped superimposed lobes with smooth appearances and occasional ramparts similar to those found in Martian fluidized ejecta (Mouginis-Mark, 1981). Although Cozobi is the only crater in the Fejokoo quadrangle interpreted to have fluidized ejecta deposits, these types of flows are common on Ceres globally with the preponderance of them located between $60^{\circ} \mathrm{S}$ and $60^{\circ} \mathrm{N}$ (Schmidt et al., 2017). All of the flow features around Cozobi (Fig. 11d) have thicknesses on the order of a few 10s of meters as inferred from the DTM.

3.4.2.5. Takel crater. This $22 \mathrm{~km}$ diameter crater centered at $51^{\circ} \mathrm{N}$, $280^{\circ} \mathrm{E}$ in the high topography province is the smallest well preserved complex crater in the Fejokoo quadrangle. It has a relatively asymmetric rim with the northeastern portion rising $\sim 1 \mathrm{~km}$ higher than the average crater rim. Takel is $\sim 2 \mathrm{~km}$ deep with respect to the average rim height. A moderately sized mass wasting feature ( $\sim 7.5 \mathrm{~km}$ long by $\sim 5.1 \mathrm{~km}$ wide) with pronounced lateral ridges up to $\sim 30 \mathrm{~m}$ tall on the northern crater wall is the dominant geologic feature within Takel (Fig. 11e). A larger bright material region associated with a blocky spine-like protrusion is located on the interior of the southern crater wall.

3.4.2.6. Jarovit. The $66 \mathrm{~km}$ diameter Jarovit, centered at $68^{\circ} \mathrm{N}$, $285^{\circ} \mathrm{E}$ is the northernmost named feature to protrude into the Fejokoo quadrangle. This highly degraded and asymmetric crater displays significant recession of the crater rim in two main locations, one on the north rim and the other on the southwest rim. The recess on the southwest rim is also host to the most outstanding geologic feature in Jarovit is a large, broad, interior facing mass wasting feature (Fig. 11f). This lobate deposit is $\sim 22 \mathrm{~km}$ long, $\sim 15 \mathrm{~km}$ wide, and $\sim 200 \mathrm{~m}$ thick at its eastern terminus. The total drop high from the lobate deposit's scarp to its eastern toe is $\sim 4.1 \mathrm{~km}$. Unlike the rest of Jarovit, the scalloped recess where the mass wasting feature originates displays sharp undegraded morphologies suggesting it is relatively young compared to its host crater. The landslide's scarp does not display significant uplift relative to the remaining rim of Jarovit, nor does there appear to be any obvious ejecta or mass wasting exterior to this recess. Thus this feature has been interpreted as being most likely an impact triggered landslide by a relatively small impactor, such that the triggering impact crater was eroded during the subsequent landslide.

3.4.2.7. Roskva and Dada craters. Roskva and Dada are two proximal craters centered at $59^{\circ} \mathrm{N}, 333^{\circ} \mathrm{E}$ and $59^{\circ} \mathrm{N}, 337^{\circ} \mathrm{E}$, respectively (Fig. 11g). The $\sim 22 \mathrm{~km}$ diameter Roskva crater is roughly symmetrical in shape and in topography. Roskva has a generally flat floor that lies $\sim 2.5 \mathrm{~km}$ below the average rim height. The floor itself is characterized by curvilinear ridges and large scale hummocks (100-200 m tall and 700-1000 m wide). A poorly developed central peak with a prominence of $\sim 250 \mathrm{~m}$ is located in the center. Roskva crosscuts Dada along their shared rim indicating it is the younger of the two.

The $12 \mathrm{~km}$ diameter Dada crater is a simple bowl-shaped crater with a maximum depth $\sim 1000 \mathrm{~m}$ below the average rim height. The floor of Dada sits $\sim 1000 \mathrm{~m}$ above the average depth of Roskva, and the shared rim between the two craters rises only $\sim 300 \mathrm{~m}$ above the floor of Dada. A sinuous scarp in the western portion of Dada indicates possible collapse of a section of the crater into Roskva. This observation is difficult to confirm as the downrange section of any mass wasting falls within a currently shadowed region as seen by Dawn.

3.4.2.8. Oxo crater. Oxo (Fig. 11h) is the most striking geologic feature in the Fejokoo quadrangle. With an absolute average reflectance of $\sim 0.07$ at $550 \mathrm{~nm}$, Oxo is the second brightest feature on Ceres behind Cerealia Facula, the central bright dome in Occator (absolute reflectance $\sim 0.3$ at $550 \mathrm{~nm}$ wavelength); the average Ceres has an absolute reflectance of $\sim 0.035$ (Nathues et al., 2015). The $\sim 10 \mathrm{~km}$ diameter crater, centered at $42.2^{\circ} \mathrm{N}, 359.6^{\circ} \mathrm{E}$, is shared between the Ac-5 Fejokoo and Ac- 2 Coniraya quadrangles with the preponderance of the feature lying within the former. The crater interior to the SE rectangular terrace is a simple bowl shape (maximum depth $\sim 1200 \mathrm{~m}$ below the average height of the undisturbed western rim) that rises towards the east (Fig. 12) due mainly to the large bounding ridge trending NE-SW located at its southeastern margin. The large rectangular terrace slump block found in the southeastern half of the crater dominates the internal morphology of Oxo. The terrace, which measures $\sim 8.2 \mathrm{~km}$ along strike and is $\sim 2.1 \mathrm{~km}$ wide, sits $\sim 1000 \mathrm{~m}$ above the base of Oxo, which puts it at roughly the same elevation as the northwest rim. The main bounding scarp rises an additional $\sim 1000 \mathrm{~m}$ above the terrace block itself. The bulk of this elevation gain occurs over $\sim 1300 \mathrm{~m}$ equating to an average slope of $\sim 38^{\circ}$ (Fig. 12c). This is significantly higher than $24^{\circ}$, which is representative of the slope of the northwestern rim.

Unlike most other craters in the Fejokoo quadrangle Oxo has a photometrically distinct and well-defined ejecta blanket surrounding it. The majority of the ejecta falls within a skewed rectangular region $\sim 44 \mathrm{~km}$ long by $\sim 31 \mathrm{~km}$ wide centered at $42.4^{\circ} \mathrm{N}, 359.7^{\circ} \mathrm{E}$ with the long axis trending NE-SW. Like the crater itself Oxo's ejecta is substantially brighter on average than the mean Ceres, yet it still displays a high degree of small scale structure on the order of hundreds of meters in the form of bright and dark material rays. The dark material rays are on average $10 \%$ less bright than the background cratered terrain, while the bright material rays can be up to 3 times as bright as the background terrain in some locations. These alternating curvilinear rays are found to radiate away 

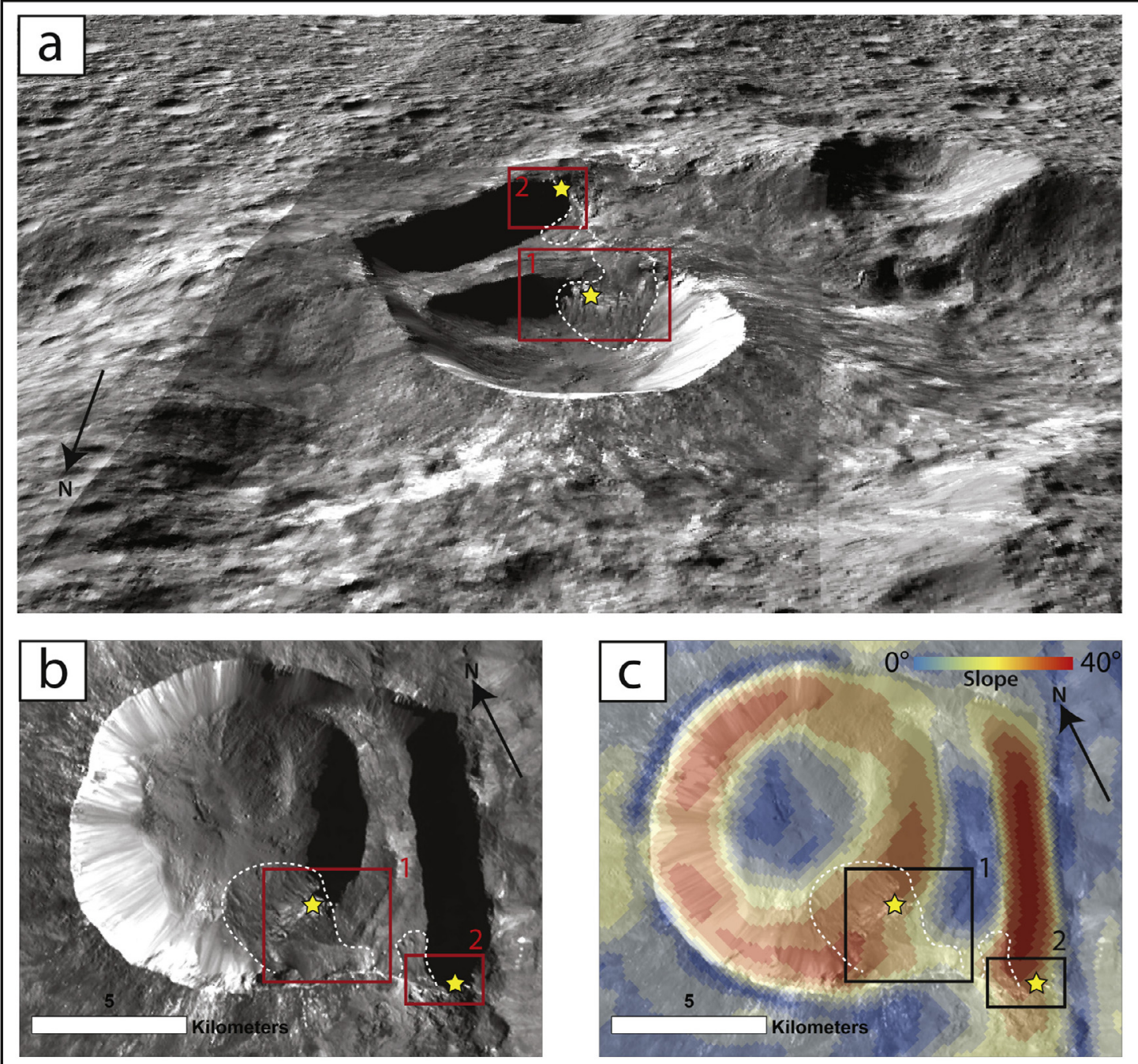

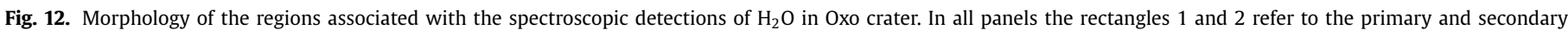

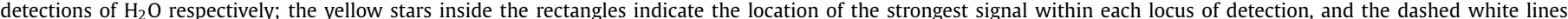

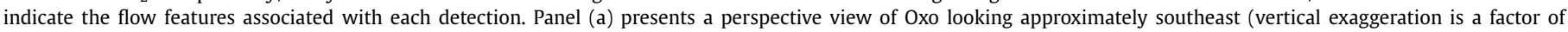

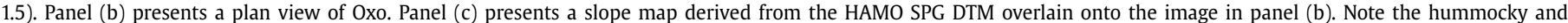

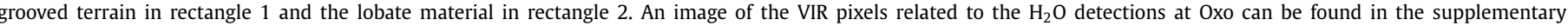
materials (S5). (For interpretation of the references to color in this figure legend, the reader is referred to the web version of this article.)

predominantly from the western half of Oxo. Additionally, Oxo is the most spectroscopically variable feature in the Fejokoo quadrangle. Oxo and its surrounding ejecta appear strongly blue in color composite R (Fig. 6) meaning it has a negative spectral slope in the visible wavelengths. This negative slope is in contrast to the majority of the Fejokoo quadrangle, which generally has a positive slope (i.e. reddish tinge in color composite R). Regions on Ceres with negative spectral slopes have been associated with younger surface ages (Jaumann et al., 2016; Schmedemann et al., 2016).

Initial VIR observations of Oxo detected significant $\mathrm{H}_{2} \mathrm{O}$ absorption bands at $1.65 \mu \mathrm{m}$ and $2.00 \mu \mathrm{m}$ (Combe et al., 2016), which partially motivated the detailed geological mapping effort presented here (Fig. 13). Two major detections were made in Oxo; the primary is centered at $359.8^{\circ} \mathrm{E}, 41.8^{\circ} \mathrm{N}$ (Fig. 12 , rectangle 1 ), and the weaker secondary detection is centered at $359.9^{\circ} \mathrm{E}, 41.4^{\circ} \mathrm{N}$ (Fig. 12 , rectangle 2) (Combe et al., 2016). This mapping campaign revealed four geologic/morphologic features in and around Oxo of particular noteworthiness: (1) an extensive boulder field, (2) a parallel to sub-parallel system of scarps, fissures, and normal faults; (3) lobate hummocky floor material associated with the primary
$\mathrm{H}_{2} \mathrm{O}$ detection (lobate material hummocky bright geologic unit in Fig. 13), and (4) lobate mass wasting deposits associated with the secondary detection (lobate material geologic unit in Fig. 13). A large base map image of Oxo and its ejecta is provided in the supplementary materials (S6).

Using LAMO resolution FC images 77 very large boulders (hereafter referred to as megablocks) $\sim 100-140 \mathrm{~m}$ in diameter (which is the smallest scale that allows for reasonable interpretation) were identified in and around Oxo. The megablocks external to the crater are found only within $\sim 4 \mathrm{~km}$ of the northern and northwestern portions of the rim indicating a possible downrange direction for the Oxo forming impact. The megablocks in the crater's interior are found on all the constituent geologic units with a relative scarcity on the bright lobate hummocky material, which is associated with the primary $\mathrm{H}_{2} \mathrm{O}$ detection. Boulders/megablocks have been observed around only a handful of other geologically fresh craters on Ceres (Schröder et al., 2016). In general, the scarcity of large blocks on the surface of Ceres appears broadly consistent with Basilevsky et al., (2015)'s prediction that the average lifetime of boulders on Ceres should be 


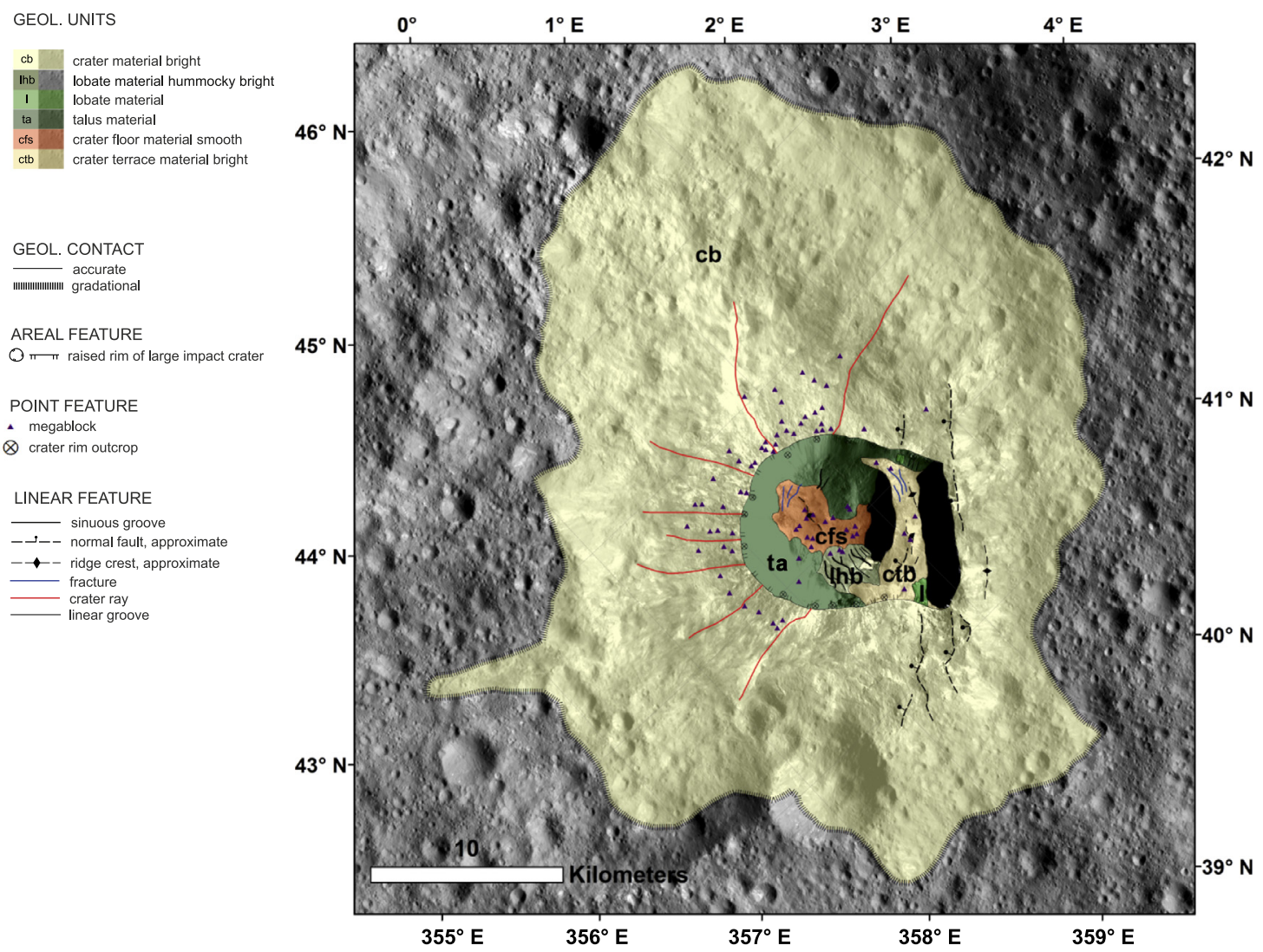

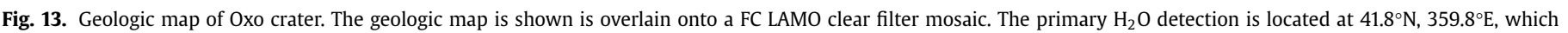

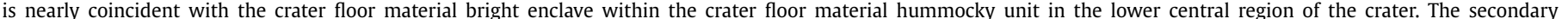

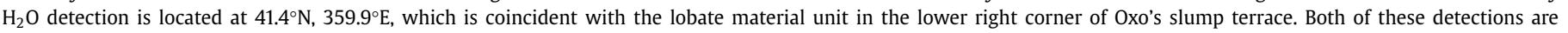

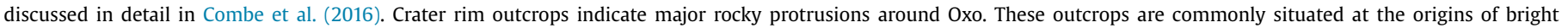
and dark material streaks. (For easier interpretation of this figure, the reader is referred to the color version of this figure found within the web edition of this article.)

$\sim 0.03$ times that of boulders on the moon, assuming this scaling factor applies equally to all sizes of boulders/megablocks. However, other factors such as the observed lack of a cohesive cerean bedrock unit are not accounted for in this interpretation. The presence of megablocks at Oxo supports the relatively young crater counting model age estimates of $\sim 3-4$ Ma reported here (Fig. 14). Crater counting at Oxo is particularly difficult due to its young age and morphology; it should be noted that its age has been reported as young as $\sim 500$ ka by other authors (Schmedemann et al., 2016).

The numerous linear tectonic features found parallel and subparallel to the main bounding scarp of Oxo's terrace block are located both exterior and interior to the crater. The exterior set of scarps and ridges are located to the south and southeast of the main bounding scarp along a broad ridge flanking Oxo, and are interpreted as normal faults. These faults range between $1-4 \mathrm{~km}$ in length, and have inferred vertical displacements of tens to approximately $100 \mathrm{~m}$. The most obvious fault located in the interior of Oxo is the main terrace bounding fault located along the SE margin of the crater. Based on the slump-like behavior of the main terrace block this fault, which has a vertical displacement of $\sim 1000 \mathrm{~m}$, is likely a listric-style normal fault. The remaining set of interior arcuate fissures and scarps are located exclusively on the main terrace block. These features range in length from $<1-3.5 \mathrm{~km}$ in length, and in the case of faults have vertical displacements on the order of tens of meters whereas the largest fissure open near the northern margin of the terrace is $\sim 100 \mathrm{~m}$ wide. Vertical displacements were inferred from shadow measurement taken on individual FC frames, and informed by the DTM where the faults were resolved.
The lobate hummocky material unit is $\sim 3.3 \mathrm{~km}$ wide along the widest part of its toe, and $\sim 2.7 \mathrm{~km}$ long from the top of the inner most scarp to the edge of the toe; it faces towards the center of Oxo with a mean slope of $\sim 21^{\circ}$, which is shallower than the surrounding crater walls. The primary $\mathrm{H}_{2} \mathrm{O}$ detection is most closely associated with the high albedo bright unit near the southern end of the hummocky unit, but the VIR pixels showing the greatest $\mathrm{H}_{2} \mathrm{O}$ absorptions are located immediately east of the bright unit within the shadow of the terrace block. The lobate hummocky unit appears covered with spatulate lobes hundreds of meters wide separated by numerous linear, and three major curvilinear and bifurcating grooves that run the length of the slope.

The secondary $\mathrm{H}_{2} \mathrm{O}$ detection on the terrace block is mostly coincident with two lobate mass wasting features that are both $\sim 1300 \mathrm{~m}$ long by $\sim 400 \mathrm{~m}$ wide with mean slopes of $\sim 22^{\circ}$. These deposits are roughly as wide as their source and have broad steepfronted toes with apparent terminal ramparts. The thickness of these toes is estimated to be on the order of tens of meters; however, the HAMO-based DTM is ambiguous at small scales in this region of high topographic contrast.

3.4.2.9. Duginavi crater. Centered at $39^{\circ} \mathrm{N}, 4^{\circ} \mathrm{E}$ (Fig. 11i), the $155 \mathrm{~km}$ diameter Duginavi crater only partially extends into the southeast/south central portion of the Fejokoo quadrangle, and is the host crater for the previously mentioned Oxo crater. Duginavi is highly degraded and heavily cratered. The crater floor extends to a maximum depth of $\sim 5 \mathrm{~km}$ below the highest segment of the rim, and the center is dominated by a large degraded central peak. The northeastern portion of Duginavi contains a large unnamed tholus that appears unrelated to the subdued central peak. 

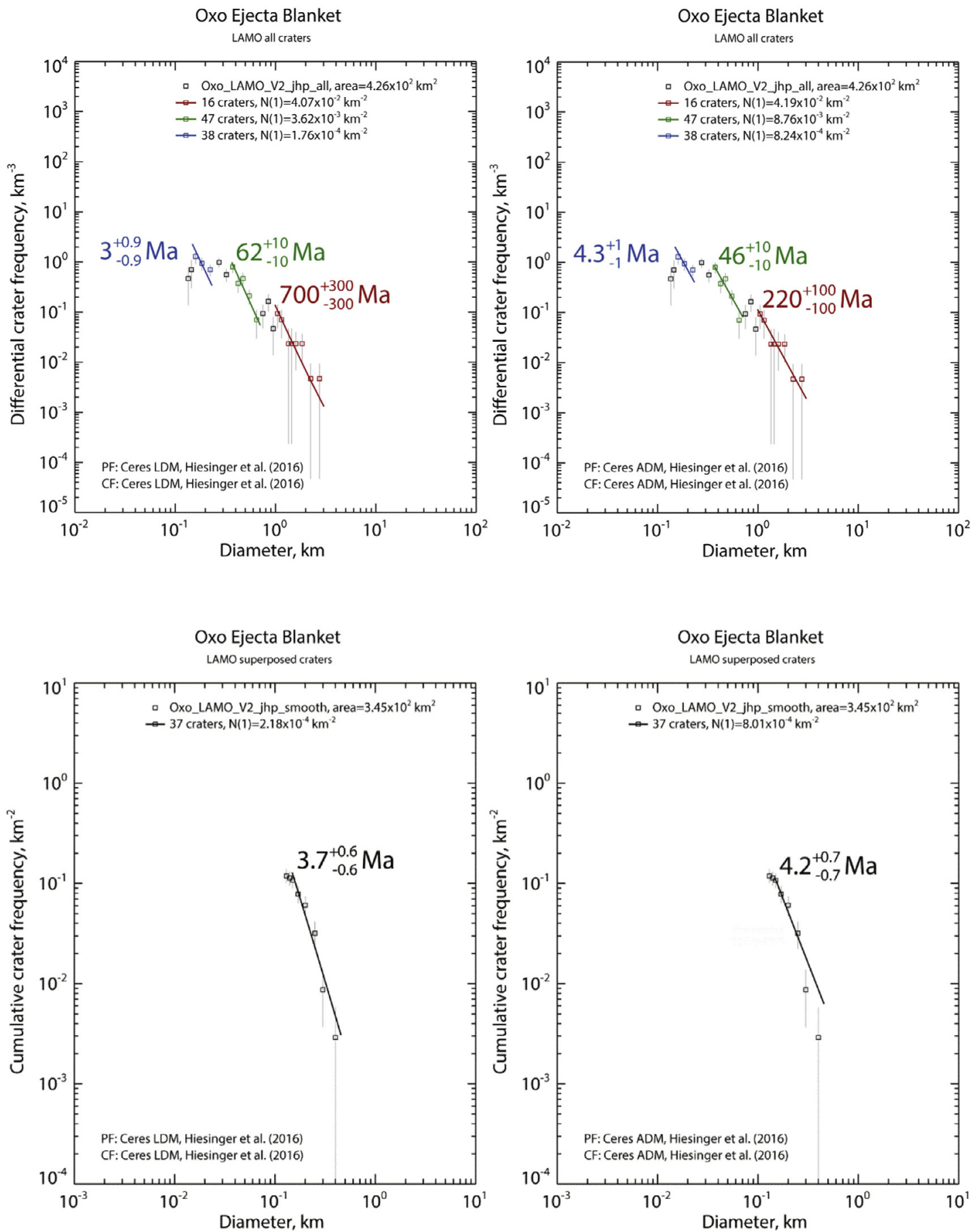

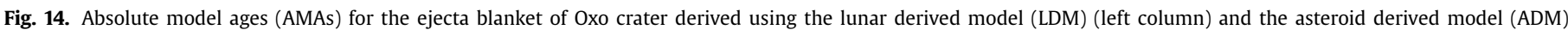

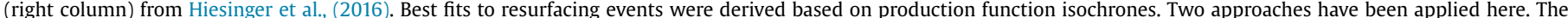

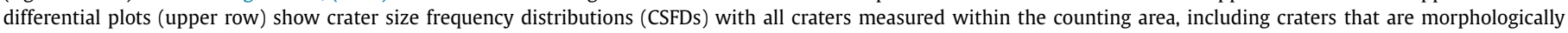

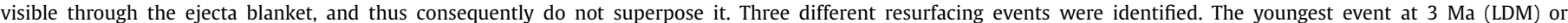

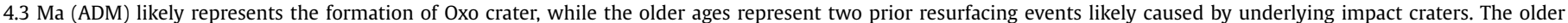

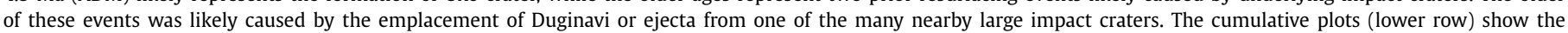

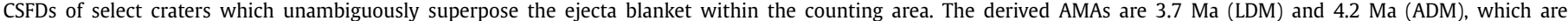
nearly identical with the youngest resurfacing events of the differential plots. Consequently, we interpret them to represent the deposition of Oxo's ejecta blanket.

\section{Discussion}

\subsection{Distribution and implications of tholi in the Fejokoo quadrangle}

The distribution of tholi in the Fejokoo quadrangle appear to be biased towards the low topography province in the southern portion of the quadrangle, which we recall from Section 3.2 is es- sentially a northern extension of the smooth lowlands found ubiquitously in the Ac-10 Rongo quadrangle. Approximately $68 \%$ of all tholi and mons on Ceres identified by a global mapping campaign (Buczkowski et al., 2016) are found on the same hemisphere that includes the Ac-5 Fejokoo Quadrangle within a $\sim 120^{\circ}$ band of longitude and $\sim 120^{\circ}$ band of latitude centered at $0^{\circ} \mathrm{N}, 0^{\circ} \mathrm{E}$. This portion of the surface accounts for only $\sim 25 \%$ of the total surface 
area of Ceres. Most of these features exist within the aforementioned smooth lowlands (USGS: http://planetarynames.wr.usgs.gov/ images/ceres.pdf).

Of Ceres' tholi/mons features Ahuna Mons (Fig. 8) is the most striking, and the best studied. Located in the Ac-10 Rongo Quadrangle, it has been interpreted as an extrusive cryovolcanic edifice, and is morphologically similar to viscous lava domes on other planetary bodies (Ruesch et al., 2016). The tholi in the Fejokoo quadrangle have significantly more degraded surfaces and moderately shallower slopes than Ahuna Mons, but are morphometrically similar to it in prominence and areal extent (Table I). Sori et al., (2017) postulated that the large tholi on Ceres may be viscously relaxed cryovolcanic edifices akin to ancient versions of Ahuna Mons. These authors argue that if these features are sufficiently ice rich ( $>40 \%$ by volume) they should viscously relax over geologic time; however, the high ice content and relatively short relaxation timescale of these features calculated by Sori et al., (2017) is at odds with the several hundred-million-year surface age of the cratered terrain in which they are found in the Fejokoo quadrangle (Hiesinger et al., 2016). The Sori et al., (2017) timescale can however be increased by an order of magnitude by manipulating ice content, rheology, grain size, and thermal parameters.

Additionally, the spectral similarities between Hosil, Mikeli, Central Aymuray, North Aymuray, and Kwanzaa identified by VIR in the $2.70 \mu \mathrm{m}$ and $3.06 \mu \mathrm{m}$ region, although subtle, differentiate these tholi from the background cratered terrain (Fig. 10). The spectral similarities observed by VIR are independent of the tholi's illumination conditions. These spectral similarities imply similar local surface compositions and/or textures that differ from the average cratered terrain in the Fejokoo quadrangle, which would be unlikely if these tholi were created solely by impact cratering.

The four southeastern most tholi (Kwanzaa tholus and the Aymuray tholi) are also weakly associated with a significant positive Bouger gravity anomaly. In comparison, Ahuna Mons is strongly associated with a large positive regional Bouger gravity anomaly (Ermakov et al., 2016). The remaining tholi in the Fejokoo quadrangle are not associated with either positive or negative Bouger gravity anomalies.

Despite these similarities, the degradation states of the Fejokoo quad tholi, and their prominences on the order of the depths of the major impact craters in Ac-5, make it impossible to eliminate the possibility that they are residual topography created by impacting, rather than constructional features, using the methods employed in this mapping study. This is especially the case for South Aymuray, which has no outstanding spectral features. This leads to the open questions of whether they are genetically related, and how/if they relate to the regional low topography province. Further analysis of high-resolution LAMO DTMs and regional elemental/mineralogical composition data from GRaND and VIR will undoubtedly shed more light onto these enigmas (e.g. determining if the broader low-lying regions has a unique elemental signature).

\subsection{Morphological interpretation of $\mathrm{H}_{2} \mathrm{O}$ at $\mathrm{Oxo}$ crater}

Using a linear spectral mixing approach to model the VIR data, Combe et al. (2016) determined that $\mathrm{H}_{2} \mathrm{O}$ ice best reproduced the spectral signature seen at Oxo; however, they did not conclude that this material is unambiguously water ice due to the fact that it should not be stable at this location on the surface over a time period greater than $10^{4}-10^{5}$ years for a snow-like deposit, or $10^{9}$ years for a deposit composed of cohesive blocks of ice (Hayne and Aharonson, 2015). The fact that a spectral mixing model derived from several different species of $\mathrm{H}_{2} \mathrm{O}$-bearing carbonate, sulfate, and chloride salts could also, albeit more poorly, emulate the results obtained by VIR further obfuscated a simple interpretation. However, at 3 Ma Oxo is young and ice preservation may occur.
Here morphological observations are considered to further constrain this interpretation around the two major sites of $\mathrm{H}_{2} \mathrm{O}$ detection at Oxo.

The primary detection falls within a bright crater material enclave within the bright hummocky lobate material unit in the south of the crater. The secondary detection lies partially over a lobate material unit, the shadow cast by the main terrace scrap, and a portion of the southern rim. Both of these regions are morphologically distinct within Oxo.

The broad lobate hummocky deposit (Fig. 12 rectangle 1) associated with the primary detection has bulbous lobes separated by subdued grooves, no obvious source depression or scarp, and a slope of $\sim 21^{\circ}$. From the morphology, we interpret this lobate feature as being similar to a debris avalanche and/or ice cemented flow as observed on both the Earth and Mars (e.g. De Blasio, 2011; Matsuoka et al., 2005; Barsch, 1992; Carr and Schaber, 1977). Given the brightness and intensity of the primary $\mathrm{H}_{2} \mathrm{O}$ detection situated on this deposit (Fig. 12 rectangle 1, yellow star) it is likely that this small patch, while still a part of the main flow, was exposed by a recent local landslide.

We adopt the term ice cemented flow as a non-specific descriptor for flows whose morphology is most analogous to terrestrial and Martian rock glaciers. Ice cemented flows typically have spatulate lobes with hummocks and concave-down morphologies (Fig. 15a). In many terrestrial and Martian cases, these features are formed through a combination of true creep (i.e. strain is accommodated by ice crystal deformation), basal sliding, and granular flow. All of which could plausibly be occurring at mid to high latitudes on Ceres at the present time (Savigny and Morgenstern, 1986). True rock glaciers and permafrost lobes in terrestrial environments have been observed to creep easily with $\sim 50 \%$ ice by volume, but have been documented exhibiting some creeping behavior at as low as $\sim 30 \%$ ice by volume (Darrow et al., 2016).

Due to Ceres' low obliquity the average diurnal surface temperature at Oxo remains relatively constant throughout the cerean year. This temperature, predicted by Hayne and Aharonson (2015) to be $\sim 150 \mathrm{~K}$, is warm enough such that it is plausible for ice-silicate mixtures to behave in a manner similar to those found on Earth. However, the poleward facing slope of Oxo, which hosts the mass wasting features of interest, is likely considerably colder than the estimated average temperature of $\sim 150 \mathrm{~K}$. Although the degree to which ice-rich Martian deposits flow is still an open question, numerical simulations suggest that viscous flow plays a significant role in the morphological evolution of icy scarps near the north pole of Mars, where thermal conditions approach those found at Oxo (Sori et al., 2016). The scarps modeled by Sori et al., (2016) are notably steeper than the Oxo deposits with slopes measured between $60^{\circ}-70^{\circ}$

Unlike ice cemented flows, debris avalanches are a relatively rapid type of granular flow that can display a multitude of different morphological traits. They can be either monodirectional and cohesive, or fluid-like and dispersive. They typically originate from an obvious scarp and have a tongue or droplet-like shape. They sometimes have longitudinal furrows that terminate normal to the frontal toe. Usually debris avalanches have a relatively flat surface profile and lateral levees, but these traits are not universal (Fleming et al., 1989; Evans et al., 1993; Strom, 2006). Of particular relevance to the primary mass wasting feature in Oxo are spread debris avalanches that have compact proximal bodies which meld into the source scarp and have a continuously thinning distal margin (Strom, 2006).

Generic granular flows and debris flows throughout the solar system often produce features with similar characteristics to debris avalanches, ice cemented flows, and the cerean flows in question. In general, it is a non-trivial task to differentiate between these types of flows using remote sensing data, even at LAMO resolution 


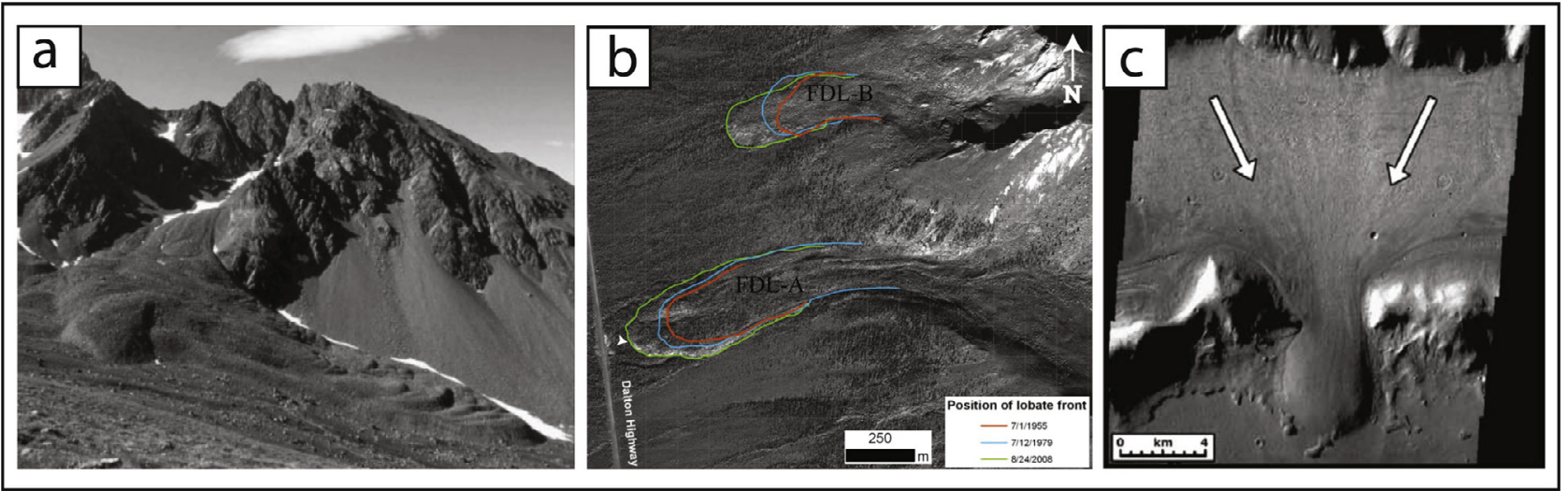

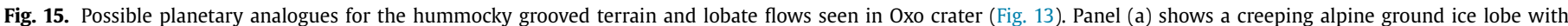

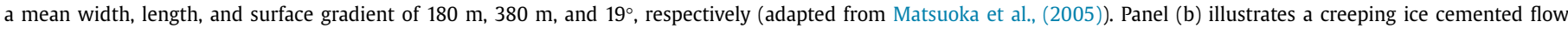

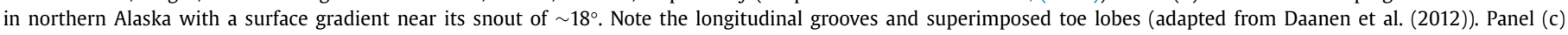
shows a debris covered glacier on Mars, arrows indicate direction of flow. Themis image V12057009 (adapted from Head et al., (2010)).

and with spectrally derived compositional knowledge. This makes it beyond the capabilities of this study to explicitly determine the nature of these flow features, but we do use the available Dawn data to determine a preferred interpretation.

The lobate flows (Fig. 12 rectangle 2) associated with the secondary detection also have characteristics similar to the feature found coincident with the primary detection. The illumination profile of these flows indicates that they have concave-down spatulate toes that are thick relative to the main trunks of the flows, and they have very little divergence along their lengths except towards the snouts. These traits, especially the concavity of the main flow and the presence of multiple spatulate toes that branch off from the main trunk near its terminus, are consistent with terrestrial and Martian ice cemented flows, but uncommon in most types of debris avalanches (Fig. 15b and 15c) (Haeberli et al., 2006; Evans et al., 1993; Strom, 2006). The compact nature of this flow indicates a significant degree of internal friction that would be unlikely if its rheology was controlled by hydrated phyllosilicates (Watkins et al., 2015). This degree of cohesion is not noted in the flow associated with the primary detection. In particular, the presence of multiple cleft terminal snouts is most consistent with the interpretation that they are ice cemented flows not debris avalanches, but this possibility cannot be excluded.

In contrast, mass wasting on the gravitationally similar asteroid Vesta typically manifests as either large rotational slumps with well-developed terraces and whose scarps are wide compared to their run-out length, or as intra-crater deposits that have been interpreted as dry granular flows (Krohn et al., 2014). Rotational slumping is observed within the Fejokoo quadrangle (e.g. in Fejokoo and Oxo craters), but usually at smaller scales and without the same degree of terrace development found on Vesta. Most of the intra-crater granular flows on Vesta tend to be amorphous and reminiscent of terrestrial talus deposits rather than discrete landslides; although examples of well-developed landslides do exist (e.g. Fig. 13c and Fig. 17 from Krohn et al., 2014). In general, vestan landslides have diffusive and tapered margins as opposed to the more abrupt and texturally distinct morphologies associated with cerean examples. Where vestan landslides do exhibit a compact, concave-down morphology, with abrupt and texturally distinct margins it is typically due to topographic channeling. The cerean flows of interest in Oxo are minimally constrained by topography. Vestan flows do not exhibit multiple cleft snouts emerging from a single flow.

The aforementioned morphological properties of the cerean flows of interest in Oxo and the lack of similar morphological fea- tures on the predominantly anhydrous asteroid Vesta, which has multiple documented cases of lobate deposits interpreted as dry granular flows (Krohn et al., 2014), indicate a fundamental compositional and/or mechanical difference between these two objects within their top few hundred meters. Based on this observation, their individual morphologies, and the Combe et al. (2016) $\mathrm{H}_{2} \mathrm{O}$ detection we interpret the primary mass wasting feature within Oxo as similar to a granular debris flow and/or ice cemented flow as seen on the Earth and Mars, and the secondary mass wasting features as similar to an ice cemented flow or a highly modified debris avalanche where ground ice is significantly altering its mechanical and rheological properties. Furthermore, we conclude that the most plausible principal explanation for the morphological differences observed between the Oxo flows and vestan landslides is the presence of significant quantities of ground ice on Ceres; however, other compositional and mechanical differences such as the presence of hydrated silicates and various salt species on Ceres, or global grain size differences between Vesta and Ceres cannot be ruled out as major causative factors. This interpretation is further supported by GRaND results that predict the emergence of a porespace-saturating surface ice table near Oxo's latitude (Prettyman et al., 2016). The interpretation that these features are analogous to ice bearing flows on other solar system bodies provides context and a framework for interpreting other similar features on Ceres, as well as placing a lower bound on their water ice volume fraction of $\sim 30-50 \%$. Their localized and discrete nature also implies that if these flows are ice controlled, ground ice is distributed inhomogeneously within the upper few hundred meters of Ceres with an enriched region coinciding with these features; at least in the vicinity of Oxo crater. Inhomogeneously distributed ground ice could also account for the limited evidence of viscously relaxed craters and slopes on Ceres, and has previously been suggested by Bland et al., (2016) as a possible explanation for the morphological discrepancy between Coniraya and Vinotonus craters in the Ac-2 quadrangle. Regardless of interpretation, the aforementioned observations demonstrate that despite similar thermal, gravitational, and orbital environments there exist forms of mass wasting on Ceres that have no morphological equivalent on Vesta.

\subsection{Distribution, Style, and implications of mass wasting and lobate flow features in the Fejokoo quadrangle}

A diversity of mass wasting and lobate flow features have been noted on the surface of Ceres, which have been broadly interpreted as belonging to a continuum composed of 3 archetypical endmembers (Buzckowski et al., 2016; Schmidt et al., 2016; Schmidt 


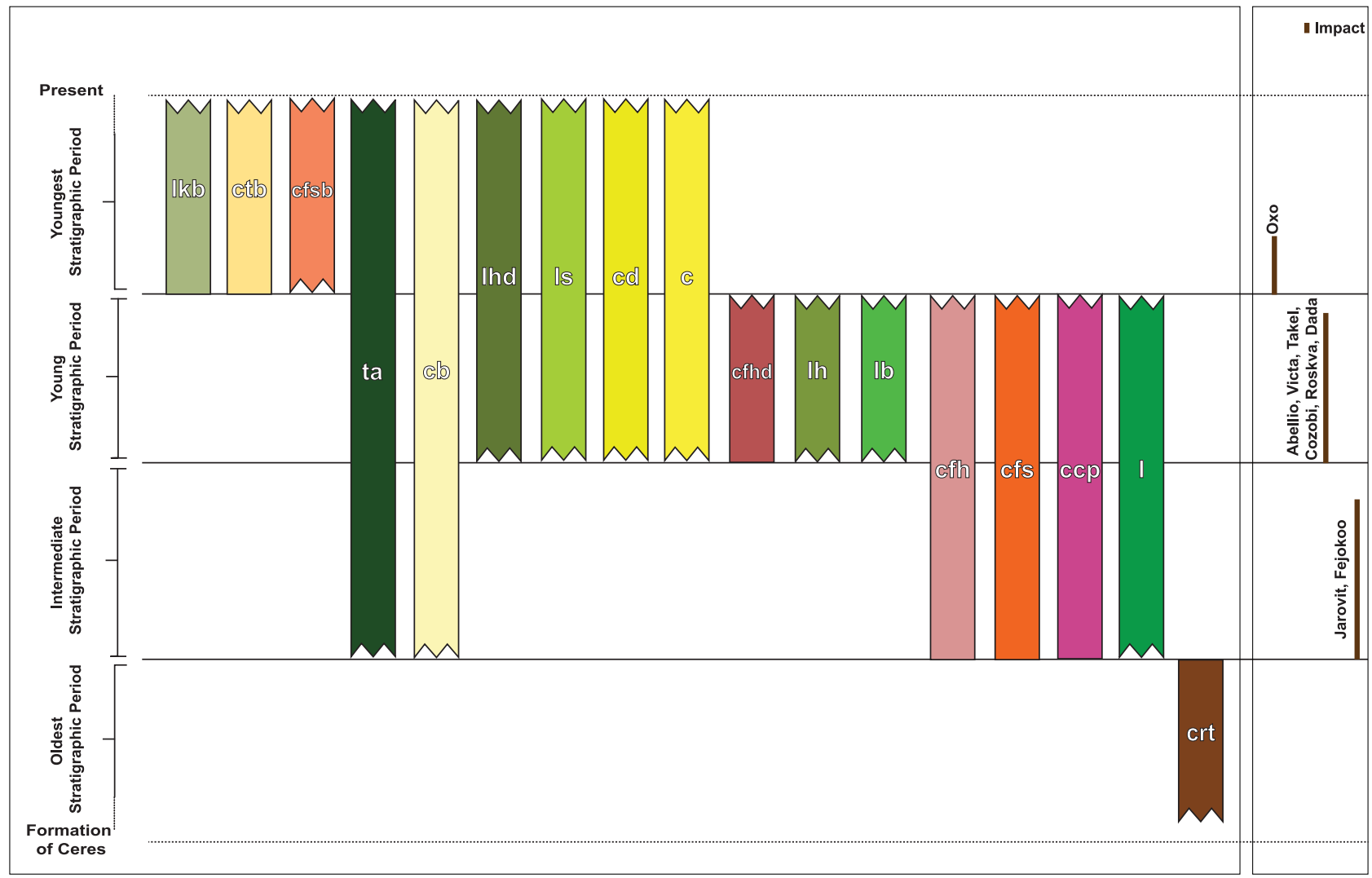

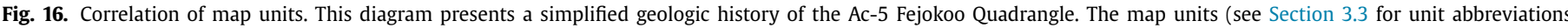

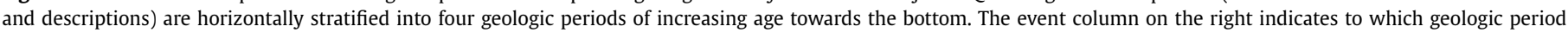

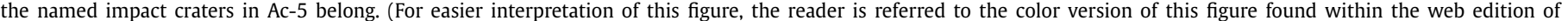
this article.)

et al., 2017): Type 1 flows, which occur at high latitudes, have concave-down profiles, steep snouts, longitudinal and sometimes lateral groves, and high height-to-runout $(\mathrm{H} / \mathrm{L})$ ratios (generally $0.3-0.7$ ) relative to Type 2 and 3 flows. Type 2 flows, which occur at all latitudes (but most abundantly in mid-latitudes), typically have a sheeted spatulate appearance, are generally smooth, have a lower degree of curvature, and lower $\mathrm{H} / \mathrm{L}$ ratios than Type 1 flows (generally $\sim 0.2$ ). Schmidt et al., (2016 and 2017) have suggested that Type 1 and 2 flows are possibly ground ice influenced landslides/ice cemented flows and long run-out landslides, respectively. Type 3 flows, which occur at low to mid latitudes and are interpreted as fluidized flows similar in appearance to Martian fluidized ejecta. They typically have a thin sheeted appearance, are smooth and featureless on their surface, terminate in multiple small vshaped lobes, and have H/L ratios between 0.1-0.3 (the majority of observed example are found at the lower end of this range). For a more detailed discussion on these flow types and their properties see Buzckowski et al. (2016) and Schmidt et al., (2016; 2017).

Based on the aforementioned properties, the Fejokoo quadrangle contains well-preserved examples of all three types of flows with nine unambiguously classified features (2 Type 1 flows, 6 Type 2 flows, and 1 Type 3 flow). The majority (6) of these flows are associated with morphologically fresh appearing craters. A Type 1 flow at Oxo (the same feature that is associated with the secondary $\mathrm{H}_{2} \mathrm{O}$ detection; Fig. 12 rectangle 2), a Type 3 flow at Cozobi (Fig. 11d), and one Type 2 flow at each of Jarovit (Fig. 7d), Cozobi (Fig. 11d), and Takel (Fig. 11e). The remaining flows exist at $36^{\circ} \mathrm{N}, 337^{\circ} \mathrm{E} ; 41^{\circ} \mathrm{N}, 331^{\circ} \mathrm{E} ; 49^{\circ} \mathrm{N}, 270^{\circ} \mathrm{E}$; and $51^{\circ} \mathrm{N}, 316^{\circ} \mathrm{E}$. The former four flows are all Type 2. The affinity of these features towards apparently young craters implies that they degrade relatively quickly over geologic time.

\subsection{Simplified geologic history of the Ac-5 Fejokoo quadrangle}

Based on morphological freshness and impact crater densities, the Fejokoo quadrangle is broadly divided into four arbitrary geological periods which from oldest to youngest are termed the "Oldest period", "Intermediate period", "Young period" and "Youngest period" (Fig. 16). These periods primarily serve to delineate the relative order in which the named craters within the Fejokoo quadrangle formed.

The Fejokoo quadrangle appears to evolve very little over the portion of Ceres' history it preserves in terms of active geologic processes. The dominant geologic process that shaped this quadrangle is undeniably impact cratering. This process has clearly been the major geomorphic force since the exposure of the surface to space up until the present. Mass wasting, whether spontaneous or impact induced, has also been a major geomorphic process throughout the history of the Fejokoo quadrangle. Examples of such features are present in all but the oldest demographic of impact craters.

Given the ambiguity of how the Fejokoo quadrangle tholi formed there are multiple possible timelines for their emplacement. Any tholi that may have formed as residual topography from impact cratering were likely created early on in the history of the quadrangle due to their generally rounded profiles and location 
within the ancient cratered terrain unit. Any tholi that may have been produced as constructional features are far less constrained with respect to their time of formation. Without more knowledge of how uplift affects the texture and the ability of the cratered terrain to retain topography it is very difficult to estimate when any such tholi formation mechanism may have been active. It may be possible that these features were formed very early on, very recently, or continuously throughout the history of the Fejokoo quadrangle.

\section{Conclusions}

The geologic mapping of the Ac-5 Fejokoo Quadrangle shows that this area contains some of the most ancient terrain on Ceres. It is ubiquitously covered in cratered terrain, and shows limited but important geologic variability. The diversity comes mainly in the form of crater material units and lobate deposits associated with fresh impact craters.

Tholi in the Fejokoo quadrangle share many physical, morphometric, and geographical similarities with the presumptive cryovolcanic structure Ahuna Mons. The majority of these tholi in the Fejokoo quadrangle also have similar surface compositions that differ from the surrounding cratered terrain, which makes it unlikely that they are residual topography derived from impacting.

Oxo crater is a feature of extreme importance on Ceres because of the presence of distinctive morphological units associated with water ice. The lobate deposit associated with the primary $\mathrm{H}_{2} \mathrm{O}$ detection appears morphologically analogous to ice cemented flows and/or debris avalanches seen on the Earth and Mars. The former of these analogies bolsters the interpretation that the spectroscopic detection of $\mathrm{H}_{2} \mathrm{O}$ in Oxo is of water-ice; however, the later does not. The lobate deposit associated with the secondary $\mathrm{H}_{2} \mathrm{O}$ detection is extremely similar to terrestrial and Martian ice cemented flows. This association provides a framework for interpreting other morphologically related flows and mass wasting features found throughout the Fejokoo quadrangle and Ceres as a whole. In particular, the presence of potentially ice controlled mass wasting features in Oxo demonstrates that while the upper layer of Ceres is more depleted in volatiles than expected the presence of localized enriched pockets of ground ice likely still influence surface processes.

\section{Acknowledgments}

We thank NASA, DLR, MPS, and INAF for funding and enabling the Dawn mission as well as all the members of the Dawn flight, instrument, and science teams for their efforts that led to a successful mission at Ceres and the collection and processing of the data used in this mapping study. We also thank two anonymous reviewers who provided a number of constructive comments.

\section{Supplementary materials}

Supplementary material associated with this article can be found, in the online version, at doi:10.1016/j.icarus.2017.09.035.

\section{References}

A'Hearn, M.F., Feldman, P.D., 1992. Water vaporization on Ceres. Icarus 98, 54-60. Arvidson, R., Boyce, J., Chapman, C., Fulchignoni, M., Moore, H., Neukum, G., Schultz, P., Soderblom, L., Strom, R., Woronow, A., Young, R., 1979. Standard techniques for presentation and analysis of crater size-frequency data. Icarus 37, 467-474.

Basilevsky, A.T., Head, J.W., Horz, F., Ramsley, K., 2015. Survival times of meter-sized rock boulders on the surface of airless bodies. Planet. Space Sci. 117, 312-328.

Barsch, D., 1992. Permafrost creep and rockglaciers. Permafr. Periglac. Process. 3, 175-188.
Bland, M.T., Raymond, C.A., Schenk, P.M., Fu., R.R., Kneissl, T., Pasckert, J.H., Hiesinger, H., Preusker, F., Park, R.S., Marchi, S., King, S.D., Castillo-Rogez, J.C., Russell, C.T., 2016. Composition and structure of the shallow subsurface of Ceres revealed by crater morphology. Nat. Geosci. 9, 538-542.

Buczkowski, D.L., Schmidt, B.E., Williams, D.A., Mest, S.C., Scully, J.E.C., Ermakov, A., Preusker, F., Schenk, P., Otto, K., Hiesinger, H., O'Brien, D., Marchi, S., Sizemore, H., Hughson, K.H.G., Chilton, H., Bland, M.T., Byrne, S., Schorghofer, N., Ruesch, O., Platz, T., Jaumann, R., Roatsch, T., Sykes, M.V., Nathues, A., De Sanctis, M.C., Raymond, C.A., Russell, C.T., 2016. The geomorphology of Ceres. Science 353 (6303). doi:10.1126/science.aaf4332.

Buczkowski, D.L., Williams, D.A., Scully, J.E.C., Mest, S.C., Crown, D.A., Schenk, P.M., Jaumann, R., Roatsch, T., Preusker, F., Platz, T., Nathues, A., Hoffman, M., Schaefer, M., Marchi, S., De Sanctis, M.C., Raymond, C.A., Russell, C.T., 2017. The geology of the Occator Quadrangle of dwarf planet Ceres: floor-fractured craters and other geomorphic evidence of cryomagmatism. Icarus, accepted for publication, this issue.

Burbine, T.H., 1998. Could G-class asteroids be the parent bodies of the CM chondrites? Meteor. Planet. Sci. 33, 253-258.

Carr, M.H., Schaber, G.G., 1977. Martian permafrost features. J. Geophys. Res. 82, 4039-4054.

Castillo-Rogez, J.C., McCord, T.B., 2010. Ceres' evolution and present state constrained by shape data. Icarus 205, 443-459.

Castillo-Rogez, J.C., Bowling, T., Fu, R.R., McSween, H.Y., Raymond, C.A., Rambaux, N., Travis, B., Marchi, S., O’Brien, D.P., Johnson, B.C., King S.D., Bland, M.T., Neveu, M., De Sanctis, M.C., Ruesch, O., Sykes, M.V., Prettyman, T.H., Park, R.S., Russell, C.T., 2016. Loss of Ceres' icy shell from impacts: assessment and implications. In: Proceedings of the Forty-Seventh Lunar and Planetary Science Conference (LPSC XLVII) Abs. \#3012.

Combe, J.-P., McCord, T.B., Tosi, F., Ammannito, E., Carrozzo, F.G., De Sanctis, M.C., Raponi, A., Byrne, S., Landis, M., Hughson, K.H.G., Raymond, C.A., Russell, C.T., 2016. Detection of local $\mathrm{H}_{2} \mathrm{O}$ exposed at the surface of Ceres. Science 353 (6303). doi:10.1126/science.aaf3010.

Coradini, A., Turrini, D., Federico, C., Magni, G., 2011. Vesta and Ceres: crossing the history of the solar system. Space Sci. Rev. 163, 25-40.

Darrow, M.M., Gyswyt, N.L., Simpson, J.M., Daanen, R.P., Hubbars, T.D., 2016. Frozen debris lobe morphology and movement: an overview of eight dynamic features, southern Brooks Range, Alaska. The Cryosphere 10, 977-993.

De Blasio, F.V., 2011. Introduction to the Physics of Landslides. Springer.

De Sanctis, M.C., Coradini, A., Ammannito, E., Filacchione, G., Capria, M.T., Fonte, S., Magni, G., Barbis, A., Bini, A., Dami, M., Ficai-Veltroni, I., Preti, G., VIR Team, 2011. The VIR spectrometer. Space Sci. Rev. 163, 329-369.

De Sanctis, M.C., Ammannito, E., Raponi, A., Marchi, S., McCord, T.B., McSween, H.Y. Capaccioni, F., Capria, M.T., Carrozzo, F.G., Ciarniello, M., Longobardo, A., Tosi, F., Fonte, S., Formisano, M., Frigeri, A., Giardino, M., Magni, G., Palomba, E., Turrini, D., Zambon, F., Combe, J.-P., Feldman, W., Jaumann, R., McFadden, L.A., Pieters, C.M., Prettyman, T., Toplis, M., Raymond, C.A., Russell, C.T., 2015. Ammoniated phyllosilicates with a likely outer solar system origin on (1) Ceres. Nature 528, 241-244.

De Sanctis, M.C., Raponi, A., Ammannito, E., Ciarniello, M., Toplis, M.J., McSween, H.Y., Castillo-Rogez, J.C., Ehlmann, B.L., Carrozzo, F.G., Marchi, S., Tosi, F., Zambon, F., Capaccioni, F., Capria, M.T., Fonte, S., McCord, T.B., Capria, M.T., Formisano, M., Frigeri, A., Giardino, M., Longobardo, A., Magni, G., Palomba, E., McFadden, L.A., Pieters, C.M., Jaumann, R., Schenk, P., Mugnuolo, R., Raymond, C.A., Russell, C.T., 2016. Bright carbonate deposits as evidence of aqueous alteration on (1) Ceres. Nature 536, 54-57.

Ermakov, A.I, Zuber, M.T., Smith, D.E., Fu, R.R., Raymond, C.A., Park, R.S, Russel, C.T. 2016. Evaluation of Ceres' compensation state. In: Proceedings of the Forty-Seventh Lunar and Planetary Science Conference (LPSC XLVII) Abs. \#1708.

Ermakov, A.I., Fu, R.R., Castillo-Rogez, J.C., Raymond, C.A., Park, R.S., Preusker, F., Russell, C.T., Smith, D.E., Zuber, M.T., 2017. Constraints on Ceres' internal structure and evolution from its shape and gravity measured by the Dawn spacecraft. J. Geophys. Res. 122. doi:10.1002/2017JE005302.

Evans, S.G., Hunger, O., Enegren, E.G., 1993. The Avalanche Lake rock avalanche, Mackenzie Mountains, Northwest Territories, Canada: description, dating, and dynamics. Geol. Surv. Can. Contrib. 45693, 749-768.

Fleming, R.W., Ellen, S.D., Algus, M.A., 1989. Transformation of dilative and contractive landslide debris into debris flows - an example from Marin County, California. Eng. Geol. 27, 201-223.

Haeberli, W., Hallet, B., Arenson, L., Elconin, R., Humlum, O., Kääb, A., Kaufmann, V. Ladanyi, B., Matsuoka, N., Springman, S., Mühll, D.V., 2006. Permafrost creep and rock glacier dynamics. Permafr. Periglac. Process. 17, 189-214.

Hayne, P.O., Aharonson, O., 2015. Thermal stability of ice on Ceres with rough topography. J. Geophys. Res. Planets 120, 1567-1584.

Head, J.W., Marchant, D.R., Dickson, J.L., Kress, A.M., Baker, D.M., 2010. Northern mid-latitude glaciation in the late Amazonian period of Mars: criteria for the recognition of debris-covered glacier and valley glacier landsystem deposits. Earth Planet. Sci. Lett. 194, 306-320.

Hiesinger, H., Marchi, S., Schmedemann, N., Schenk, P., Pasckert, J.H., Neesemann, A., O’Brien, D.P., Kneissl, T., Ermakov, A.I., Fu, R.R., Bland, M.T., Nathues, A., Platz, T., Williams, D.A., Jaumann, R., Casstillo-Rogez, J.C., Ruesch, O., Schmidt, B., Park, R.S., Preusker, F., Buczkowski, D.L., Russell, C.T., Raymond, C.A., 2016. Cratering on Ceres: implications for its crust and evolution. Science 353 (6303). doi:10.1126/science.aaf4759.

Jaumann, R., Stephan, K., Krohn, K., Matz, K.-D., Otto, K., Neumann, W., Kneissl, T., Schmedemann, N., Schroeder, S., Tosi, F., De Sanctis, M.C., Preusker, F., Buczkowski, D.L., Capacioni, F., Carsentry, U., Elgner, S., vod der Gathen, I., Gieb- 
ner, T., Hiesinger, H., Hoffmann, M., Kersten, E., Li, J.-Y., McCord, T.B., McFadden, L., Mottola, S., Nathues, A., Neesemann, A., Raymond, C.A., Roatsch, T., Russell, C.T., Schmidt, B., Schulzeck, F., Wagner, R., Williams, D.A., 2016. Age-dependent morphological and compositional variations on Ceres. In: Proceedings of the Forty-Seventh Lunar and Planetary Science Conference (LPSC XLVII) Abs. \#1455.

Konopliv, A.S., Asmar, S.W., Bills, B.G., Mastrodemos, N., Park, R.S., Raymond, C.A., Smith, D.E., Zuber, M.T., 2011. The Dawn gravity investigation at Vesta and Ceres. Space Sci. Rev. 163, 461-486.

Konopliv, A.S., Park, R.S., Vaughan, A.T., Bills, B.G., Asmar, S.W., Ermakov, A.I., Rambaux, N., Raymond, C.A., Castillo-Rogez, J.C., Russell, C.T., Smith, D.E., Zuber, M.T., 2018. The Ceres gravity field, spin pole, rotation period and orbit from the Dawn radiometric tracking and optical data. In Icarus 299, 411-429. doi:10.1016/ j.icarus.2017.08.005, ISSN 0019-1035

Krohn, K., Jaumann, R., Otto, K., Hoogenboom, T., Wagner, R., Buczkowski, D.L., Garry, B., Williams, D.A., Yingst, R.A., Scully, J., De Sanctis, M.C., Kneissl, T., Schmedemann, N., Kersten, E., Stephan, K., Matz, K.-D., Pieters, C.M., Preusker, F., Roatsch, T., Schenk, P., Russell, C.T., Raymond, C.A., 2014. Mass movement on Vesta at steep scarps and crater rims. Icarus 244, 120-132.

Küppers, M., O’Rourke, L., Bockelée-Morvan, D., Zakharov, V., Lee, S., von Allmen, P., Carry, B., Teyssier, D., Marston, A., Müller, T., Crovisier, J., Barucci, M.A., Moreno, R., 2014. Localized sources of water vapour on the dwarf planet (1) Ceres. Nature 505, 525-527.

Kneissl, T., van Gasselt, S., Neukum, G., 2011. Map-projection-independent crater size-frequency determination in GIS environments - new software tool for ArcGIS. Planet. Space Sci. 59, 1243-1254.

Kneissl, T., Schmedemann, N., Neesemann, A., Raymond, C.A., Russell, C.T., 2014. Crater counting on small bodies - the influence of topography-related distortions. In: Proceedings of the Forty-Fifth Lunar and Planetary Science Conference (LPSC XLV) Abs. \#2398.

Kneissl, T., Michael, G.G., Platz, T., Walter, S.H.G., 2015. Age determination of linear surface features using the Buffered Crater Counting approach - case studies of the Sirenum and Fortuna Fossae graben systems on Mars. Icarus 250, 384-394.

Li, J.-Y., Reddy, V., Nathues, A., Le Corre, L., Izawa, M.R.M., Clouts, E.A., Sykes, M.V., Carsentry, U., Castillo-Rogez, J.C., Hoffmann, M., Jaumann, R., Krohn, K., Mottola, S., Prettyman, T.H., Schaefer, M., Schenk, P., Schröder, S.E., Williams, D.A., Smith, D.E., Zuber, M.T., Konopliv, A.S., Park, R.S., Raymond, C.A., Russell, C.T., 2016. Surface albedo and spectral variability of Ceres. Astrophys. J. Lett. 817, L22.

Marchi, S., Ermakov, A.I., Raymond, C.A., Fu, R.R., O’Brien, D.P., Bland, M.T., Ammannito, E., De Sanctis, M.C., Bowling, T., Schenk, P., Scully, J.E.C., Buczkowski, D.L., Williams, D.A., Hiesinger, H., Russell, C.T., 2016. The missing large impact craters on Ceres. Nat. Commun. doi:10.1038/ncomms12257, article \# 12257.

Matsuoka, N., Ikeda, A., Date, T., 2005. Morphometric analysis of solifluction lobes and rock glaciers in the Swiss Alps. Permafr. Periglac. Process. 16, 99-113.

McCord, T.B., Sotin, C., 2005. Ceres: evolution and current state. J. Geophys. Res. Planets 110, E05009.

Mouginis-Mark, P., 1981. Ejecta emplacement and models of formation of Martian fluidized ejecta craters. Icarus 45, 60-76.

Michael, G.G., Neukum, G., 2010. Planetary surface dating from crater size - frequency distribution measurements: partial resurfacing events and statistical age uncertainty. Earth Planet. Sci. Lett. 294, 223-229.

Nathues, A., Hoffmann, M., Schaefer, Le Corre, L., Reddy, V., Platz, T., Cloutis, E.A., Christensen, U., Kneissl, T., Li, J.-Y., Mengel, K., Schmedemann, N., Schaefer, T., Russell, C.T., Applin, D.M., Buczkowski, D.L., Izawa, M.R.M., Keller, H.U., O’Brien, D.P., Pieters, C.M., Raymond, C.A., Ripken, J., Schenk, P.M., Schmidt, B.E., Sierks, H., Sykes, M.V., Thangjam, G.S., Vincent, J.-B., 2015. Sublimation in bright spots on (1) Ceres. Nature 528, 237-240.

Park, R.S., Konopliv, A.S., Bills, B.G., Rambaux, N., Castillo-Rogez, J.C., Raymond, C.A., Vaughan, A.T., Ermakov, A., Zuber, M.T., Fu, R.R., Toplis, M.J., Russell, C.T., 2016. Interior structure of dwarf planet Ceres from measured gravity and shape. Nature 537, 515-517.

Pasckert, J.H., Hiesinger, H., Ruesch, O., Williams, D.A., Naß, A., Kneissl, T., Mest, S.C., Buczkowski, D.L., Scully, J.E.C., Schmedemann, N., Jaumann, R., Roatsch, T., Preusker, F., Nathues, A., Hoffmann, M., Schäfer, De Sanctis, M.C., Raymond, C.A., Russell, C.T., 2017. Geologic mapping of the Ac-2 Coniraya Quadrangle of Ceres from NASA's Dawn mission: implications for a heterogeneously composed crust. Icarus doi:10.1016/j.icarus.2017.06.015.

Platz T., Nathues A., Sizemore H.G., Crown D.A., Hoffmann M., Schäfer, Schmedemann N., Kneissl T., Neesemann A., Mest S.C., Buczkowski D.L., Ruesch O., Hughson K.H.G., Nass A., Williams D.A., Preusker F. Geologic mapping of the Ac-10 Rongo quadrangle of Ceres. Icarus. In Press this issue, https://doi.org/10.1016/j. icarus.2017.08.001.

Porco, C.C., Baker, E., Barbara, J., Beurle, K., Brahic, A., Burns, J.A., Charnoz, S., Cooper, N., Dawson, D.D., Del Genio, A.D., Denk, T., Dones, L., Dyudina, U., Evans, M.W., Giese, B., Grazier, K., Helfenstein, P., Ingersoll, A.P., Jacobsson, R.A., Johnsom, T.V., McEwen, A., Murray, C.D., Neukum, G., Owen, W.M., Perry, J., Roatsch, T., Spitale, J., Squyres, S., Thomas, P.C., Tiscareno, M., Turtle, E., Vasavada, A.R., Veverka, J., Wagner, R., West, R., 2005. Cassini imaging science: initial results on Phoebe and Iapetus. Science 307, 1237-1242.

Preusker, F., Scholten, F., Matz, K.-D., Elfner, S., Jaumann, R., Roatsch, T., Joy, S.P., Polanskey, C.A., Raymond, C.A., Russell, C.T., 2016. Dawn at Ceres - shape model and rotation state. In: Proceedings of the Forty-Seventh Lunar and Planetary Science Conference (LPSC XLVII) Abs. \#1954.

Prettyman, T.H., Feldman, W.C., McSween, H.Y., Dingler, R.D., Enemark, D.C., Patrick, D.E., Storms, S.A., Hendricks, J.S., Morgenthaler, J.P., Pitman, K.M.,
Reedy, R.C., 2011. Dawn's gamma ray and neutron detector. Space Sci. Rev. 163, 371-459.

Prettyman, T.H., Yamashita, N., Toplis, M.J., McSween, H.Y., Schorghofer, N. Marchi, S., Feldman, W.C., Castillo-Rogez, J.C., Forni, O., Lawrence, D.J., Ammannito, E., Ehlmann, B.L., Sizemore, H.G., Joy, S.P., Polanskey, C.A., Rayman, M.D., Raymond, C.A., Russell, C.T., 2016. Extensive water ice within Ceres' aqueously altered regolith: evidence from nuclear spectroscopy. Science 355 (6320) 55-59.

Rivkin, A.S., Volquardsen, E.L., Clark, B.E., 2006. The surface composition of Ceres: discovery of carbonates and iron-rich clays. Icarus 185, 563-567.

Roatsch, T., Kersten, E., Matz, K.-D., Preusker, F., Scholten, F., Jaumann, R., Raymond, C.A., Russell, C.T., 2016a. Ceres survey atlas derived from Dawn framing camera images. Planet. Space Sci. 121, 115-120.

Roatsch, T., Kersten, E., Matz, K.-D., Preusker, F., Scholten, F., Jaumann, R., Raymond, C.A., Russell, C.T., 2016b. High-resolution Ceres high altitude mapping orbit atlas derived from Dawn framing camera images. Planet. Space Sci. 129 $103-107$.

Ruesch, O., Platz, T., Schenk, P., McFadden, L.A., Castillo-Rogez, J.C., Byrne, S., Preusker, F., O’Brien, D.P., Schmedemann, N., Williams, D.A., Li, J.-Y., Bland, M.T., Hiesinger, H., Kneissl, T., Neesemann, Schaefer, M., Pasckert, J.H., Schmidt, B., Buczkowski, D.L., Sykes, M.V., Nathues, A., Roatsch, T., Haffmann, M., Raymand, C.A., Russell, C.T., 2016. Cryovolcanism on Ceres. Science 353 (6303). doi:10.1126/science.aaf4286.

Ruesch O., McFadden L., Williams D.A., Hughson K.H.G., Pasckert J.H., Scully J.E.C., Kneissl T., Roatsch T., Nass, A., Preusker F., Scmedemann N., Marchi S., Hiesinger H., Jaumann R., Nathues A., Raymond C.A., Russell C.T. Geology of Ceres' north pole quadrangle from Dawn FC imaging data. Icarus. In Press this Issue, https://doi.org/10.1016/j.icarus.2017.09.036.

Russell, C.T., Raymond, C.A., Ammannito, E., Buczkowski, D.L., De Sanctis, M.C. Hiesinger, H., Jaumann, R., Konopliv, A.S., McSween, H.Y., Nathues, A., Park, R.S. Pieters, C.M., Prettyman, T.H., McCord, T.B., McFadden, L.A., Mottola, S., Zuber, M.T., Joy, S.P., Polanskey, C., Rayman, M.D., Castillo-Rogez, J.C., Chi, P.J., Combe, J.-P., Ermakov, A., Fu, R.R., Hoffmann, M., Jia, Y.D., King, S.D., Lawrence, D.J., Li, J.-Y., Marchi, S., Preusker, F., Roatsch, T., Ruesch, O., Schenk, P., Villarreal, M.N., Yamashita, N., 2016. Dawn arrives at Ceres: exploration of a small volatile-rich world. Science 353, 1008-1010.

Savigny, K.W., Morgenstern, N.R., 1986. In situ creep properties in ice-rich permafrost soil. Can. Geotech. J. 23, 504-514.

Schenk, P.M., 1989. Crater formation and modification on the icy satellites of Uranus and Saturn: depth/diameter and central peak occurrence. J. Geophys. Res. 94, 3813-3832.

Schmedemann, N., Kneissl, T., Needemann, A., Stephan, K., Jaumann, R., Krohn, K. Michael, G.G., Matz, K.D., Otto, K.A., Raymond, C.A., Russell, C.T., 2016. Timing of optical maturation of recently exposed material on Ceres. Geophys. Res. Lett. 43, 11987-11993.

Schmidt, B.E., Hughson, K.H.G., Chilton, H.T., Scully, J.E.C., Platz, T., Nsthues, A., Sizemore, H., Bland, M.T., Byrne, S., Marchi, S., O’Brian, D.P., Schorghofer, N., Hiesinger, H., Jaumann, R., Lawrence, J., Buczkowski, D., Castillo-Rogez, J.C., Sykes, M.V., Schenk, P.M., De Sanctis, M.C., Mitri, G., Formisano, M., Li, J.-Y., Reddy, V., LeCorre, L., Russell, C.T., Raymond, C.A., the Dawn Science and Operations Teams, 2016. Ground ice on Ceres. In: Proceedings of the Forty-Seventh Lunar and Planetary Science Conference (LPSC XLVII) Abs. \#2677.

Schmidt, B.E., Hughson, K.H.G., Chilton, H.T., Scully, J.E.C., Platz, T., Nsthues, A., Sizemore, H., Bland, M.T., Byrne, S., Marchi, S., O'Brian, D.P., Schorghofer, N., Hiesinger, H., Jaumann, R., Pasckert, J.H., Lawrence, J.D., Castillo-Rogez, J.C., Sykes, M.V., Schenk, P.M., De Sanctis, M.C., Mitri, G., Formisano, M., Li, J.-Y, Reddy, V., LeCorre, L., Russell, C.T., Raymond, C.A., 2017. Geomorphological evidence for ground ice on dwarf planet Ceres. Nat. Geosci. 10, 338 343.

Schröder, S.E., Maue, T., Gutiérrez Marqués, P., Mottola, S., Aye, K.M., Sierks, H. Keller, H.U., Nathues, A., 2013. In-flight calibration of the Dawn framing camera. Icarus 226, 1304-1317.

Schröder, S.E., Mottola, S., Matz, K.-D., Roatsch, T., 2014. In-flight calibration of the Dawn framing camera II: Flat fields and stray light correction. Icarus 234, 99-108.

Schröder, S., Carsentry, U., Neesemann, A., McFadden, L., Marchi, S., Otto, K., Schenk, P., Jaumann, R., Raymond, C., Russell, C., 2016. Boulders on Ceres. Geophys. Res. Abstr. 18, Abst. \# EGU2016-12693.

Schröder, S., Mottola, S., Carsenty, U., Ciarnielo, M., Jaumann, R., Li, J-Y., Longobardo, A., Palmer, E., Pieters, C., Preusker, F., Raymond, C.A., Russell, C.T., 2017. Resolved spectrophotometric properties of the Ceres surface from Dawn framing camera images. Icarus 288, 201-225.

Scully, J.E.C., Buczkowski, D.L., Neesemann, A., Williams, D.A., Mest, S.C., Raymond, C.A., Nass, A., Hughson, K.H.G., Kneissl, T., Pasckert, J.H., Ruesch, O., Frigeri, A. Marchi, S., Combe, J.-P., Schmedemann, N., Schmidt, B.E., Chilton, H.T., Russell, C.T., Jaumann, R., Preusker, F., Roatsch, T., Hoffmann, M., Nathues, Schaefer, M. Ermakov, A. Ceres' Ezinu quadrangle: a heavily cratered region with evidence for localized subsurface water ice and the context of Occator crater. Icarus. In Press this issue (no doi assigned yet).

Sierks, H., Keller, H.U., Jaumann, R., Michalik, H., Behnke, T., Bubenhagen, Fo Büttner, I., Casentry, U., Chritensen, U., Enge, R., Fiethe, B., Gutiérrez Marqués, P., Hartwig, H., Krüger, H., Kühne, W., Maue, T., Mottola, S., Nathues, A., Reiche, K.-U., Richards, M.L., Toatsch, T., Schröder, S.E., Szemerey, I., Tschentscher, M., 2011. The Dawn framing camera. Space Sci. Rev. 163, $263-$ 327. 
Sori, M.M., Byrne, S., Hamilton, C.W., Landis, M.E., 2016. Viscous flow rates of icy topography on the north polar layered deposits of Mars. Geophys. Res. Lett. 43, 541-549. doi:10.1002/2015GL067298.

Sori, M.M., Byrne, S., Bland, M.T., Bramson, A.M., Ermakov, A.I., Hamilton, C.W., Otto, K.A., Ruesch, O., Russell, C.T., 2017. The vanishing cryovolcanoes of Ceres. Geophys. Res. Lett. 44. doi:10.1002/2016GL072319.

Strom, A., et al., 2006. Morphology and internal structure of rockslides and rock avalanches: grounds and constraints for their modelling. In: Evans, S.G., et al. (Eds.), Landslides from Massive Rock Slope Failure. Springer, pp. 305-326.

Thomas, P.C., Parker, J.M., McFadden, L.A., Russell, C.T., Stern, S.A., Sykes, M.V., Young, E.F., 2005. Differentiation of the asteroid Ceres as revealed by its shape. Nature 437, 224-226.

Watkins, J.A., Ehlmann, B.L., Yin, A., 2015. Long-runout landslides and the longlasting effects of early water activity on Mars. Geology 43, 107-110. doi:10.1130/ G36215.1.
Williams, D.A., Yingst, R.A., Garry, W.B., 2014. Introduction: the geological mapping of Vesta. Icarus 244, 1-12.

Williams, D.A., Buczkowski, D.L., Mest, S.C., Scully, J.E.C., 2017. Introduction: the geologic mapping of Ceres. Icarus.

Yingst, R.A., Mest, S.C., Berman, D.C., Garry, W.B., Williams, D.A., Buczkowski, D. Jaumann, R., Pieters, C.M., De Sanctis, M.C., Frigeri, A., Le Corre, L., Preusker, F., Raymond, C.A., Reddy, V., Russell, C.T., Roatsch, T., Schenk, P.M., 2014. Geological mapping of Vesta. Planet. Space Sci. 103, 2-23.

Zolotov, M.Y., 2009. On the composition and differentiation of Ceres. Icarus 204 183-193. 